\title{
Evaluating the biological effectiveness of fully and partially protected marine areas
}

Marija Sciberras ${ }^{1 *}$, Stuart R Jenkins ${ }^{1}$, Michel J Kaiser ${ }^{1}$, Stephen J Hawkins ${ }^{2}$ and Andrew S Pullin ${ }^{3}$

\begin{abstract}
Background: Marine Protected Areas (MPAs) encompass a range of protection levels, from fully protected no-take areas to restriction of only particular activities, gear types, user groups, target species or extraction periods. We synthesized the results of empirical studies that compared partially protected areas (PPA) to (i) no-take marine reserves (NTR) and (ii) to open access areas (Open), to assess the potential benefits of different levels of protection for fish and invertebrate populations.
\end{abstract}

Methods: A systematic search for relevant articles used terms describing MPAs, the biota (e.g. fish, invertebrates) and measures (e.g. density, biomass) of interest. Articles were examined for relevance using specified inclusion criteria. Included articles were appraised critically; the influence of studies whose effect of protection was identified to be confounded by habitat was examined by running a sensitivity analysis parallel to the main analysis that included all studies. Random effect meta-analysis on In-transformed response ratios was used to examine the response to protection. Subgroup analyses and meta-regression were used to explore variation in effectiveness in relation to MPA and species covariates.

Results: Synthesis of available evidence suggests that while PPAs resulted in higher values of biological metrics (density and biomass) than unprotected areas, greatest benefits were apparent in NTR areas when NTRs and PPAs were compared. For fish, the positive response to protection, whether full or partial protection, was primarily driven by targeted fish species. Although positive benefits were also apparent in non-target fish species, the results were more variable, perhaps because of fewer studies focusing on this group. Invertebrate studies were underrepresented and those available focused mainly on scallops, lobsters and sea urchins. Among the targeted species groups, benefits from partial protection relative to fished areas were highest for scallops, whereas benefits from full relative to partial protection were highest for lobsters. The examination of fish and invertebrate response to protection in terms of species richness and length was hampered by small sample sizes. There was significant variability in the magnitude of response to protection among the MPAs included in this study. The factors determining such variation were generally unclear although the size and protection regime of the PPA explained some of this variability.

Conclusions: The available evidence suggests that no-take reserves provide some benefit over less protected areas, nevertheless the significant ecological effects of partially protected areas relative to open access areas suggest that partially protected areas are a valuable spatial management tool particularly in areas where exclusion of all extractive activities is not a socio-economically and politically viable option.

A glossary of terms is given in Appendix.

Registration number: CEE-09-018

Keywords: Marine protected areas, Protection level, Fish, Invertebrates, Exploitation status, MPA design, Weighted meta-analysis

\footnotetext{
*Correspondence: marija_sciberras@yahoo.com

'School of Ocean Sciences, Bangor University, Menai Bridge, Anglesey LL59 5AB, UK

Full list of author information is available at the end of the article
} 


\section{Background}

Only in the last decade has there been recognition that marine ecosystems worldwide are suffering massive and acute declines in biodiversity and irreparable alterations to ecosystem functioning [1,2]. Marine protected areas (MPAs) and other forms of marine spatial closures are increasingly common components of management programmes for living marine resources [3]. The use of MPAs has been primarily advocated for protection of sensitive marine habitats and associated species [4,5]. Increasingly, these management tools have been recognized to make an important contribution to fishery management goals, for example for protecting essential fish habitats and promoting export of adults and larvae to adjacent areas [6-8]. Furthermore, by protecting defined areas of the sea that include both resident species and their biophysical environments, MPAs encompass an ecosystem-based approach to conservation and fisheries management, which is distinct from the traditional focus on single species management $[9,10]$.

Various types of MPAs exist, all of which can be defined based mainly upon the level of protection offered and their primary management goals. Some MPAs, such as no-take marine reserves, represent the extreme case of the precautionary approach to managing marine resources (e.g. [11]) by prohibiting all extractive (e.g. fishing) and potentially damaging (e.g. anchoring, SCUBA diving) activities. Alternatively, multiple-use marine areas seek a balance between the need to protect biodiversity while allowing some continued human use of the area. Despite the evidence of beneficial effects of no-take marine reserves for enhancing biomass and density of exploited species within the boundaries of the reserve [12-14], enhancing reproductive output $[15,16]$, rehabilitating community structure $[17,18]$ and biomass export through adult migration [19-21], the prohibition of all extractive activities in certain areas can have negative socio-economic impacts [22]. Indeed, even if reserves benefit fisheries, local fishers may be negatively affected by the loss of fishing grounds, decreased catches and increased travelling time to fishing grounds, at least in the short-term [23,24]. Consequently, no-take marine reserves may face strong opposition from fishers, making the process of reserve implementation and subsequent enforcement difficult. MPAs that impart partial protection from certain types of fishing are often advocated by groups with direct fishing interests and promoted as a 'compromise' solution allowing both protection and fishing [25].

The effectiveness of partially protected marine areas for fisheries and ecosystem restoration remains somewhat variable. Whereas some studies have recorded enhanced abundance and reproductive potential for exploited species [26,27] and recovery of community and habitat structure inside partially protected areas [7], others did not detect benefits over unprotected fished areas [25,28]. There have been numerous reviews on the effectiveness of no-take marine reserves for fish populations [29-39], however few attempts have been made to generalize the ecological effects of partially protected areas to date (but see [40]). Furthermore, previous reviews have primarily addressed work on fish. Here, we also address work on invertebrates; a taxon neglected in the past. The review by Stewart et al. [41] is, to our knowledge, the only other systematic examination of the impacts of temperate no-take areas on marine biota (fish, invertebrates and macroalgae). Here, we build on this by undertaking a global synthesis of studies by examining the efficacy of MPAs that confer varying levels of protection from extractive activities for fish and invertebrates. Systematic reviews are an improvement over conventional reviews in that they provide a comprehensive and robust assessment and summary of available evidence by following a strict methodological protocol $[42,43]$. This minimizes the chance of bias and improves transparency, repeatability and reliability of the outcomes of the review [44].

Here, we synthesize data on marine protected area (MPA) performance from studies that have made direct comparisons between (i) partially protected areas (PPA) and open access areas (Open) and (ii) partially protected areas (PPA) and no-take reserves (NTR) to examine how the level of protection inside the MPA determines benefit to fish and invertebrate populations. Species may respond differently to protection depending on the intensity of exploitation to which they are subject to outside the MPA [45-47]. Therefore, we also examined whether the response to protection differed for target and non-target species. Previous quantitative syntheses of fish populations in no-take reserves have linked the heterogeneity in response to protection among reserves to a number of MPA characteristics such as duration of protection and size of MPA [35,37-39,48]. Insights into the influence of such characteristics are fundamental for the development of a more general understanding of partially protected area effectiveness and design. Therefore, we investigate whether MPA parameters including the protection regime within the partially protected area, the duration of protection, the size of the MPA and the distance to MPA border influence the magnitude of response to protection.

\section{Objectives}

\section{Primary objective}

To examine how the level of protection inside the MPA ranging from full to partial to no protection, determines benefit to fish and invertebrate populations in terms of density, biomass, species richness and body size (length). 


\section{Secondary objectives}

To assess whether the magnitude of response to protection differs between target and non-target fish and invertebrate species.

To examine how MPA parameters including: protection regime within the partially protected area, duration of protection, size of the MPA, proximity of the protected area to open access control sites and/ or to other protected areas, influence the response to protection.

\section{Methods}

\section{Search strategy}

\section{Search terms}

We conducted a comprehensive search of peer-reviewed scientific literature and grey literature to compile a database of studies that documented and compared the biological effects of (i) no-take reserves (NTRs) to partially protected areas (PPAs), or (ii) partially protected areas (PPAs) to open access areas (Open). Owing to the diverse range of terminology referring to Marine Protected Areas (defined as discrete geographic areas of the sea that are protected by spatially explicit restrictions designated under international, national, tribal or local laws to enhance long-term conservation of natural resources therein [49]), we have attempted to make our search as comprehensive as possible by including the following search terms (" represents a wildcard):

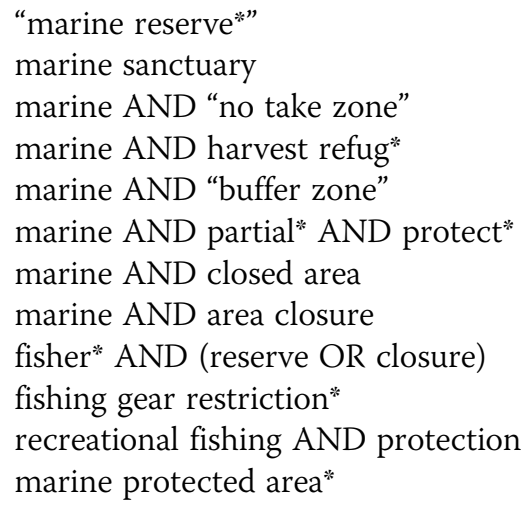

Whenever the search generated by the search terms above was too broad, we included combinations of the following terms to target specific literature relevant to the review questions:

Subject terms: "fish", "fishes", "invertebrate*"

Outcome terms: "abundance”, "density”, "size”, "length”,

"biomass", "richness", "diversity"

A full list of the search term combinations used is given in Additional file 1.

\section{Search sources}

Electronic databases Literature searches up until the end of February 2011 were carried out using the following electronic databases:

- Aquatic Sciences and Fisheries Abstracts (since 1971)

- ISI Web of Knowledge (Web of Science and Proceedings, since 1941)

- Science Direct (since 1823)

- Directory of Open Access Journals

- Copac

- Index to Theses Online

- CAB Abstracts

All references cited in the publications examined at full text were also checked for relevance, as were references and abstracts cited in the extended book of abstracts from the "European Symposium on Marine Protected Areas as a Tool for Fisheries Management and Ecosystem Conservation" that convened research from several MPA-related projects including PROTECT, EMPAFISH and BIOMEX.

Internet sources Searches were carried out in general web search engines including http://scholar.google.com/ and http://www.scirus.com/. The first fifty hits (Word and/ or PDF documents) from each search were checked for relevant pages or documents, as recommended by the CEE review guidelines.

Additional searches were carried out in specific websites listed below. In this case, each website was searched using the website's own search facilities where available, and reports and publications sections were searched in detail in all cases. Search terms were limited to 'marine protected areas' and 'marine reserves' as website search engines generally only accepted simple search terms. The websites searched were:

Joint Nature Conservation Committee: http://jncc.

defra.gov.uk/

Department for Environment, Food and Rural Affairs:

http://www.defra.gov.uk/

Centre for Environment, Fisheries \& Aquaculture

Science: http://www.cefas.defra.gov.uk/

NCCOS Center for Coastal Monitoring and

Assessment: http://ccma.nos.noaa.gov/

NOAA National Marine Protected Areas Centre:

http://mpa.gov/

California Cooperative Oceanic Fisheries Investigations: http://www.calcofi.org/

Department of Conservation, New Zealand: http:// www.doc.govt.nz/ 
Department of Sustainability, Environment, Water: http://www.environment.gov.au/

Population and Communities

\section{Article screening and study inclusion criteria}

All articles retrieved using the above search strategy were subjected to a three stage process to identify the most relevant articles for the review questions. The aim of this process was to systematically remove articles that were not relevant or did not contain relevant information or data. At each stage, if there was insufficient information to exclude an article it was retained until the next stage.

In the first instance, the title of articles was assessed using the inclusion criteria set out below, in order to remove spurious citations. Articles remaining after this filter were filtered on viewing the abstract and then the full text. In order to pass the title and abstract stage each article had to meet the following criteria:

- Relevant populations: fish, invertebrates

- Types of intervention: Marine Protected Area (where partially protected area, fishery reserves, fishery closures, gear restriction zones, buffer zones and marine reserves are all specific cases of MPAs [49])

- Types of outcome: Change in abundance (e.g. density, CPUE), biomass (or weight), species richness (or number or diversity), length (or other measure of body size).

Furthermore, the following criteria were used to accept articles at the level of full text:

- the primary study provided empirical data for outcomes quantified in (i) a NTR and a PPA, or (ii) a PPA and an Open area or (iii) a combination of all the three levels of protection (NTR vs. PPA vs. Open). Studies that presented data from within a NTR and a PPA, were included in subsequent quantitative analysis only when the two were established at the same time or within 2 years of each other

- the study presented data from after protection was implemented; or from before and after the creation of the MPA; or both (i.e. Before After Control Impact (BACI) designs)

- the study reported biological data (e.g. density or biomass) for individual species or genus or family, or reported total density or biomass for groups of fish and invertebrates separately

- the study reported exploitation status (i.e. target, non-target) for all individuals when data was given at the species, genus or family taxonomic level
- the study reported mean and sample size values (e.g. number of transects or point counts) and an appropriate variance measure (SD, SE, variance, 95\% CI) for both the MPA and its comparator.

When several studies reported on the effects of protection for the same MPA, the most recent study was retained unless the studies measured different metrics (i.e. density, biomass) or presented data at different levels of aggregation (e.g. total or individual species mean values). This avoided the risk of double counting data. Studies that presented data aggregated for several MPAs with different characteristics (e.g. [50]) were not included.

In order to assess and limit the effects of betweenreviewer differences in determining relevance, two reviewers applied the inclusion criteria to a random subset of 120 abstracts from articles accepted at the title level. A kappa statistic [51] of 0.73 was calculated, which indicates significant agreement in the selection of articles by the two reviewers.

\section{Study quality assessment}

All articles accepted at full text were critically appraised according to their study design and quality. For each article we recorded design elements that reduced susceptibility to bias. Firstly the articles were categorised according to the study design into: Before After Control Impact (BACI) studies, Control Impact (CI) studies and Before After (BA) studies (see Table 1). Ecosystem processes are spatially and temporally variable at multiple scales and these variations can obscure the detection of the effects of protection [52]. BACI studies that account for both spatial and temporal variability in the environment [53], thus allow for unambiguous inference about the effect of protection. We attempted to explore the influence of sampling design on the magnitude of the response to protection by running a sensitivity analysis using all studies and those with BACI design only. However this was not possible as the majority of studies (85\%) were based on CI studies after the MPA had already been established; only $10 \%$ were BACI data and $5 \%$ presented BA data (refer to Table 1 ).

Studies of assessment of the effect of protection may suffer from the possibility of bias due to differences in habitat among the MPA and control sites [5,54]. Some authors have argued that the apparent effect of protection is not due to protection per se, but rather due to higher-quality habitat or site-specific features in reserves before the onset of protection (e.g. [5,55]). In order to account for the systematic bias associated with baseline differences in reserve location, a sensitivity analysis was conducted parallel to the main analysis to examine the influence of including the 'habitat-confounded studies' 
Table 1 Hierarchy of study quality assessment based on sampling design

\begin{tabular}{|c|c|c|c|c|c|}
\hline \multirow[t]{2}{*}{ Sampling design } & \multicolumn{2}{|c|}{ Spatial replication } & \multicolumn{2}{|c|}{ Temporal replication } & \multirow[b]{2}{*}{$\mathrm{N}^{\circ}$ of studies } \\
\hline & Treatment (MPA) & Control & Before & After & \\
\hline \multirow[t]{2}{*}{ Beyond-BACl } & multiple & multiple & multiple & multiple & 1 \\
\hline & multiple & multiple & once & multiple & 1 \\
\hline \multirow[t]{2}{*}{$\mathrm{BACl}$} & one & one & multiple & multiple & 3 \\
\hline & one & one & once & once & 1 \\
\hline \multirow[t]{7}{*}{ After Control-Impact } & multiple & multiple & - & multiple & 7 \\
\hline & multiple & multiple & - & once & 5 \\
\hline & multiple & one & - & multiple & 4 \\
\hline & multiple & one & - & once & 2 \\
\hline & one & multiple & - & once & 1 \\
\hline & one & one & - & multiple & 18 \\
\hline & one & one & - & once & 14 \\
\hline \multirow[t]{2}{*}{ Before-After } & one & - & - & multiple & 2 \\
\hline & one & - & - & once & 1 \\
\hline
\end{tabular}

Study quality in terms of sampling design decreases down the list.

on the overall magnitude and direction of the protection effect, and report the results for the sensitivity analyses when the two differed. 'Habitat-confounded studies' refer to those studies where habitat variation, in terms of features such as substratum type, substratum composition and complexity, rugosity and exposure, was reported to be significantly different for the locations studied inside and outside the MPA.

Whenever studies reported that the enforcement of protection was poor or deteriorating during the course of the study, that study was excluded from the analyses. Additionally, study reliability is dependent on the replication of sampling effort within the MPA (e.g. the number of transects or trawls undertaken) and on the number of MPAs sampled. The level of replication (sampling effort and number of MPAs included) was recorded for each study.

\section{Data extraction}

Data extraction was undertaken using a review-specific data extraction form given in Additional file 2. Abundance (including density and CPUE), biomass, length and species richness were treated as continuous variables. Measures of abundance were used to address questions of density differences, while biomass allowed understanding of the contribution made by larger individuals. Sample sizes, means and variance (or other variance measures including standard deviation, standard error, 95\% confidence interval) values were extracted as presented from tables or within text. Data from figures were extracted using the dataextraction software TechDig v.2.

\section{Potential effect modifiers}

Several MPA characteristics that might influence the response to protection among MPAs were recorded.
These included protection regime within the MPA (i.e. activities permitted and restricted), MPA size $\left(\mathrm{km}^{2}\right)$, geographical location, time between implementation of protection and survey (MPA age), habitat type and depth. When enforcement lagged behind the establishment date, the first year of enforcement was used as the first year of protection. MPA characteristics were extracted for both the NTRs and the PPAs separately. Methodological information such as total survey area $\left(\mathrm{m}^{2}\right)$, survey method (e.g. strip transects, point counts, trawl hauls), the total number of species reported in the study and the distance between the PPA and the NTR and/or the Open area were also recorded. Whenever given, the exploitation status (i.e. targeted or non-targeted species) of fish and invertebrate species was extracted for each species.

\section{Data handling}

When data for density, biomass and species number were provided for a number of sites within and outside the MPA (e.g. [56]), mean values for each of these metrics were converted to a single mean value for the MPA and control area, respectively. The variance of the mean among sites was calculated using the following equation [57];

$$
\operatorname{var}\left(\frac{1}{m} \sum_{i=1}^{m} Y_{i}\right)=\left(\frac{1}{m}\right)^{2}\left(\sum_{i=1}^{m} V_{i}+\sum_{i \neq j}\left(r_{i j} \sqrt{V_{i}} \sqrt{V_{j}}\right)\right)
$$

where $V_{i}$ is the variance for the mean $\left(Y_{i}\right)$ at each site, $m$ is the number of sites within or outside the MPA and $r$ is the correlation coefficient that describes the extent to 
which the means at the different sites co-vary. Assuming that each site represents an independent sample, then $\mathrm{r}=0$ and the variance is just the sum of the individual variances divided by the number of sites squared.

$$
\operatorname{var}\left(\frac{1}{m} \sum_{i=1}^{m} Y_{i}\right)=\left(\frac{1}{m}\right)^{2}\left(\sum_{i=1}^{m} V_{i}\right)
$$

Whenever a study reported paired inside-outside estimates from more than one MPA, each pair was included separately in our database (e.g. [56,58-62]). When data were reported from two or more MPAs but one control area (e.g. [63-67]), data estimates within each MPA were included separately and compared to the same control. When there was more than one sampling event after MPA establishment, the most recent sampling event, representing the longest duration of protection was used. This avoids analytical problems associated with temporal autocorrelation. Furthermore, averaging data collected after, for example 2 years and 8 years of protection might underestimate the effect of protection, since effectiveness of MPAs has been shown to increase with age of MPA $[35,48]$. However, when the data were collected within the same year (most frequently over different seasons) a composite effect size was used for subsequent analysis to eliminate any seasonal effects associated with the timing of sampling. Similarly, mean data presented for different depths within the same MPA were aggregated into a composite effect size and its variance (Composite $E S_{S, D}$ and Composite $\operatorname{Var}_{S, D}$ respectively) using a fixed-effect model, whereby the weight assigned to each subgroup effect size was equal to the inverse of the within-subgroup variance (note that as the composite effect size is calculated for subgroups within the same MPA, the between-study variance, $\tau^{2}$, relevant to a random effects model is 0 , therefore a fixed-effect model is adequate in this case) [57].

\section{Data synthesis \\ MPA-level analyses}

To quantify the overall effect of protection on fish and invertebrate assemblages, we carried out a meta-analysis using effect sizes calculated for MPAs that reported total mean values, or mean values for a sizeable proportion of the fish fauna surveyed (i.e. when the data were reported for 10 or more species or for more than $75 \%$ of the total catch of all fish counts). Separate meta-analyses were carried out using density, biomass and species richness estimates to quantify the effect of (i) partial protection over no protection and of (ii) full protection over partial protection in terms of each of these measures of MPA effectiveness.
Meta-analysis The natural logarithm transformed response ratio, $\operatorname{LnRR}$ [68] was used as the effect size for density and biomass data. The response ratio is defined as the ratio of the mean density or biomass estimate measured inside and outside the MPA [68]:

$$
\operatorname{LnRR}=\operatorname{Ln}\left(\frac{\bar{X}_{P P A}}{\bar{X}_{\text {Open }}}\right)
$$

The mean difference (D) between the protected and open access area was used as the effect size for species richness, as absolute change in the number of species would be more informative to policy makers and managers. Hence, using this effect size an increase from 1 to 2 was treated the same as an increase from 10 to 11 .

$$
D=\bar{X}_{P P A}-\bar{X}_{\text {Open }}
$$

Weighted summary effect sizes ( $\overline{\operatorname{LnRR}})$ across the different MPA case studies were calculated using random effects meta-analysis, which acknowledges that differences in observed effects may be due to differences among studies such as different designs and characteristics of MPAs rather than due to sampling error alone [57].

$$
\overline{\operatorname{LnRR}}=\frac{\sum_{i=1}^{k} W_{i} \operatorname{LnRR} R_{i}}{\sum_{i=1}^{k} W_{i}}
$$

where $L n R R_{i}$ and $W_{i}$ are the effect size and weight (inverse variance) associated with each MPA included in the analysis, respectively, and $\mathrm{k}$ is the number of MPAs. For density and biomass, the weight $\left(W_{i}\right)$ was equal to the inverse of the variance calculated as [68]:

$$
V_{\text {LnRR }}=\frac{S D_{P P A}^{2}}{n_{P P A}\left(\bar{X}_{P P A}\right)^{2}}+\frac{S D_{\text {Open }}^{2}}{n_{\text {Open }}\left(\bar{X}_{\text {Open }}\right)^{2}}
$$

where $\bar{X}, S D$ and $n$ are the mean density or biomass values, the standard deviation of the mean and the sample size used for the estimation of the mean, respectively. For species richness, effect sizes were weighted based on the inverse of the natural logarithm of the total area surveyed in each study. Total survey area ranged between $0.004 \mathrm{~km}^{2}$ and $0.03 \mathrm{~km}^{2}$ for fish studies and between $6.4 \times 10^{-6} \mathrm{~km}^{2}$ and $70.08 \mathrm{~km}^{2}$ for invertebrate studies. Since the likelihood of finding new species increases with the size of area surveyed, we regarded weighting by survey area instead by sample size and variance, as a more biologically meaningful weighting scheme for species richness. Note that the effect size and the variance for comparison of the NTRs and PPAs were calculated by replacing PPA with NTR and Open with PPA in the equations above (Eq. 3, 4, 6). 
The weighted summary effects $(\overline{L n R R}), 95 \%$ confidence in the summary effect (95\% CI) $(17.9$, p.132, [57]) and prediction interval (PI) (17.10, p. 133, [57]) were calculated for each of the following variables: fish density, fish biomass, fish species richness, invertebrate density and invertebrate biomass. Whilst the confidence interval (95\% CI) quantifies the accuracy of the summary effect size, the prediction interval addresses the dispersion of the effect sizes around the 'true effect'. The prediction interval is the interval within which the effect size for a new MPA would fall $95 \%$ of the time if a MPA was selected at random from the population [57].

Positive values of the $\overline{L n R R}$ indicate greater density or biomass inside the PPA relative to Open area, or inside the NTR relative to the PPA. A decrease is represented by a ln-ratio of less than zero. The summary effect size ( $\overline{L n R R}$ ) is considered to be significantly different from zero (i.e. there is a significant either positive or negative effect of protection) when the 95\% CI does not over lap zero.

Potential correlates of response to protection Where there were sufficient data, the influence of the following potential effect modifiers on the response of fish assemblage to protection were tested; protection regime of the PPA, MPA age, size of the MPA, the total area surveyed inside and outside the MPA and the minimum distance (in $\mathrm{km}$ ) of the control sites to the MPA.

The protection regime of the PPA is described here as the combination of fishing activities prohibited and permitted inside the PPA. Based on the information extracted on the type of activities prohibited within the PPA, we divided partially protected areas into (i) 'indiscriminate' PPAs, if they prohibit fishing activities that are damaging to bottom habitats and non-target species (e.g. scallop dredging and bottom trawling) and (ii) 'discriminate' PPAs, if they prohibit activities which effect particular target species but not the surrounding environment (e.g. seine nets, long lines, spearfishing). Furthermore, based on information on the permitted activities inside the PPA, 'discriminate' PPAs were subdivided into those that allow commercial or artisanal fishing from those that allow recreational fishing or fishing for domestic purposes only. This categorization serves as an indication of the intensity of use by the different user-groups permitted to fish in the PPA. We refer to these sub-categories as 'commercial' and 'recreational', respectively. Fishing practices permitted inside 'indiscriminate' PPAs were carried out on a commercial scale. Therefore, PPAs were categorized into three discrete groups based on their protection regime: (a) indiscriminate, commercial (IdC); (b) discriminate, commercial (DC); and (c) discriminate, recreational (DR) (see Additional file 3 for details on the 'protection regime' classification scheme). It was hypothesized that indiscriminate PPAs will exhibit smaller responses to protection than discriminate PPAs as habitat restoration will have to occur before some species' populations can begin to recover. Additionally, the effect of protection for populations in DR was hypothesized to be greater than for those in DC PPAs.

A categorical mixed model meta-analysis comparing each of the three protection regime categories was carried out. Differences in effect sizes among categories were tested using $\mathrm{Q}_{\mathrm{M}}$ statistic, which partitions the total variance (of all categories about the grand mean effect size) into variance within categories and variance between categories (of category means about the grand mean) [57,69].

Meta-regression was performed to examine the effect of the following continuous variables: MPA age, MPA size, distance between MPA and control sites and total survey area on protection effectiveness. The total area surveyed inside and outside the MPA and the proximity between the MPA and the control sites were included to account for methodological variation among studies that may have a strong impact on the results obtained.

The relatively small numbers of MPAs did not permit the construction of models with multiple variables, therefore weighted simple mixed effects regression models were used throughout the analyses.

\section{Species-level analyses: exploitation status}

A considerable proportion of studies in our database presented mean and variance values for one or more individual species with different degrees of exploitation. We therefore included these studies in separate metaanalyses to determine the effect of (i) partial protection over no protection and of (ii) full protection over partial protection for target and non-target species. 'Target species' is taken to refer to those species that are primarily sought by the fishermen in a particular fishery and are the subject of directed fishing effort. This category was further subdivided into target species that were protected in both the NTR and the PPA (TP) and target species that were protected in the NTR but still allowed to be fished inside the PPA (TNP). 'Non-target species' denotes species for which fishing gear is not specifically set, although the possibility that these species are accidentally caught as by-catch cannot be ruled out.

Meta-analysis Individual species $l n$-transformed response ratios $\left(\operatorname{Ln} R R_{\mathrm{i}}\right)$ were calculated for each MPA using species density or biomass or body length estimates inside and outside the MPA. When a species was absent either inside or outside the MPA (i.e. the density or biomass estimate was zero), the species was removed from the analysis. As the 
effect sizes of individual species within a MPA are unlikely to be independent of each other, a single effect size measure for each 'exploitation status' category within each MPA was generated to handle non-independence of data [70,71]. Individual species response ratios $\left(\operatorname{Ln} R R_{i}\right)$ were therefore averaged to produce a single study-average effect size for each exploitation category (i.e. $L n R R_{T P}, L n R R_{T N P}, L n R R_{N T}$ ). The variance associated with the single study-average effect size was calculated using (Eq. 1) in the 'Data handling' section, where $Y_{i}$ is the individual species' response ratio $\left(\operatorname{LnR} R_{i}\right), V_{i}$ and $V_{j}$ are the within-study variance for species i to $\mathrm{j}, \mathrm{m}$ is the number of species within each 'exploitation status' category and $r$ is the correlation coefficient that describes the extent to which the means of two different species co-vary. Since the correlation coefficient among species within a study was never reported, a range of correlation coefficient values were used in the calculation (rho $=0,0.2,0.5,0.8,1$ ) and the analyses repeated for each value of $r$.

The effect of species 'exploitation status' on the response to protection was examined by conducting a random effects subgroup analysis using the $\mathrm{Q}_{M}$ statistic [69] to determine whether the between-group responses were significantly different. A weakness of this approach, however, is that if for example we hypothesize that duration of protection influences effect size, then the comparison of target to non-target species might be confounded by the age of the MPA. Therefore, to minimize ecological and performance biases across different studies [72], we calculated a second effect size $\left(E S_{D I F F}\right)$ that consists of the difference between target $\left(L n R R_{T P}\right)$ and non-target $\left(L n R R_{N T}\right)$ effect sizes for each MPA:

$$
\text { Effect size difference } E S_{D I F F_{i}}=L n R R_{T P_{i}}-L n R R_{N T_{i}}
$$

$$
\begin{aligned}
& \operatorname{Variance}\left(\operatorname{Var}_{D I F F}\right) \operatorname{var}\left(\operatorname{LnRR_{TP_{i}}}-\operatorname{LnRR_{NT_{i}}}\right) \\
& =\operatorname{var}_{T P_{i}}+\operatorname{var}_{N T_{i}}-2 r \sqrt{\operatorname{var}_{T P_{i}}} \sqrt{\operatorname{var}_{N T_{i}}}
\end{aligned}
$$

[57] where $E S_{D I F F_{i}}$ is the effect size difference for $M P A_{i}$, $\operatorname{var}_{T P_{i}}$ and $\operatorname{var}_{N T_{i}}$ are the variance for target-protected and non-target species for $M P A_{i}$ and $\mathrm{r}$ is the correlation coefficient (rho $=0,0.5,1$ ).

The within-MPA effect size $\left(E S_{D I F F_{i}}\right)$ was used to estimate a summary effect size across the different MPAs to determine if there were significant differences in the magnitude of response between different exploitation categories. Only the TP and NT categories for fish density, biomass and length provided a big enough sample size for formal significance testing. Results from the two approaches were cross-checked and discussed when different.
Potential correlates of response to protection As for the reserve-level analyses we examined the influence of a number of MPA characteristics on target species response to protection. As the overall response to protection was not significantly different between TP and TNP (see Results section Species-level analysis: Comparison of partial protection vs. no protection and Species-level analysis: Comparison of full vs. partial protection), we pooled the effect sizes from these two sub-categories so as to retain more power in the analysis through a bigger sample size. The sample sizes for the NT species category were too small to allow further analysis. The variables examined for the target species data were: (i) MPA age (years); (ii) size of the PPA (for comparison of PPA $v s$. Open), or alternatively, the size ratio of the NTR to the PPA (for comparison of NTR vs. PPA); (iii) PPA protection regime (for comparison of PPA vs. Open); and (iv) the proximity of the non-protected control sites to the PPA border (for comparison of PPA vs. Open), or alternatively, the distance between the borders of the no-take area and partially-protected area (for comparison of NTR vs. PPA). The distance of the NTR to the PPA was not examined for target species density as all the MPAs except for one were characterized by a zonation scheme, consisting of NTR and an adjacent PPA. Furthermore, the number of species pooled to calculate the effect size for each exploitation category was also examined because averages composed of large numbers of species may exhibit stronger positive responses due to the higher probability of including species that benefit from protection [73].

Analyses were conducted using the software package Metawin (v. 2.0: [69]) for calculation of effect size and within-study variance and in $\mathrm{R}$ using the metaphor package [74] for conducting random-effects meta-analyses.

\section{Results \\ Studies found}

The electronic database search identified 4581 potentially relevant articles. After the title inclusion stage, 675 articles were retained with an additional 198 articles from internet searches. After the abstract inclusion stage 298 articles were included with an additional 75 articles from organizational searches and bibliographies. At full text a total of 62 studies were found to be relevant and provided data for inclusion in the meta-analysis. Many studies were not included in the review because the studies lacked an adequate comparator (i.e. an open access area for PPA vs. Open comparison, and a partially protected MPA for NTR vs. PPA comparison), or studies compared no-take areas with open access areas only. Studies were excluded from full text inclusion when the 'protection regime' (i.e. the activities prohibited and/or allowed) within the MPA were not described clearly in 


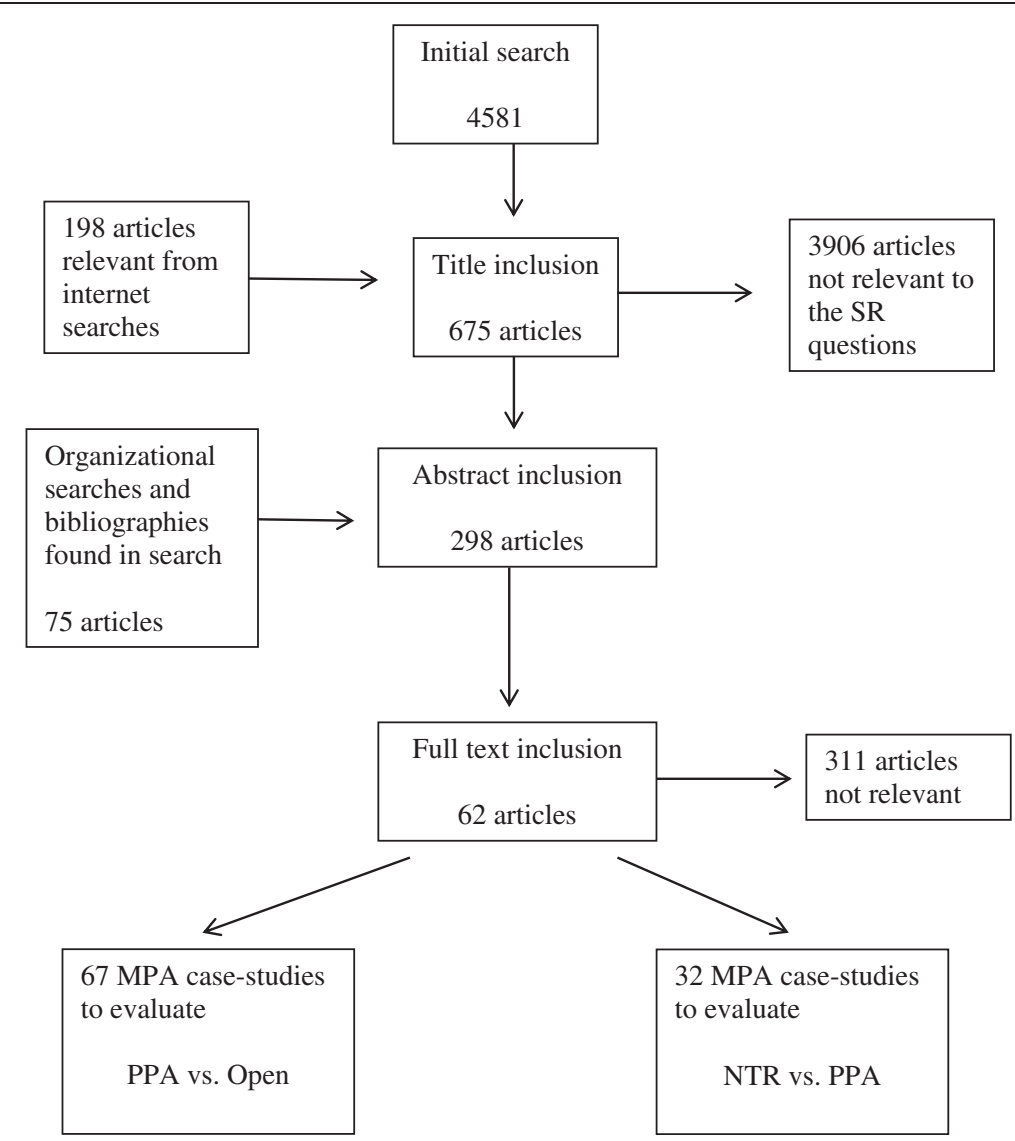

Figure 1 Flowchart of the process for identifying the articles and studies relevant to the review questions.

the study, such that it was difficult to decide whether the MPA was a NTR or a PPA. The full list of studies and reason/s as to why the study was excluded from the review at the full text stage are given in Additional file 4. The 62 studies retained at full text assessment provided data on fish or invertebrate population measures for 77 MPAs, of which 65 MPAs were used to assess partial protection over no protection and 26 MPAs were used to compare the effect of full protection over partial protection (Figure 1).

\section{Description of studies used in PPA vs. Open analysis}

The majority of the PPAs were based in North America (45\%) and Europe (29\%) (Figure 2). PPA age at the time of study ranged between 1 and 61 years; the modal age was 4 years. The size of the PPA ranged between 0.14 and $11980 \mathrm{~km}^{2} ; 24 \%(\mathrm{n}=13)$ were smaller than $2 \mathrm{~km}^{2}$, whereas $32 \%(\mathrm{n}=16)$ were larger than $50 \mathrm{~km}^{2}$. Studies of PPAs in soft sediment were under-represented compared to those carried out on hard substrata, and coral reefs were the most studied habitats (Figure 3). In total, 49 MPAs provided data on fish species, and 25 MPAs for invertebrate species. Density and biomass were the most common measures for assessment of protection on both fish and invertebrate populations (Figure 4A). The majority of MPAs were based on control-impact studies sampled only once $(39 \%, \mathrm{n}=30)$ or on multiple occasions $(34 \%, \mathrm{n}=26)$. BACI data were presented for $18 \%(n=14)$ of the MPAs, however $64 \%$ $(n=9)$ of these MPAs were from the same study [59], and thus subject to selection/performance bias. Only 2

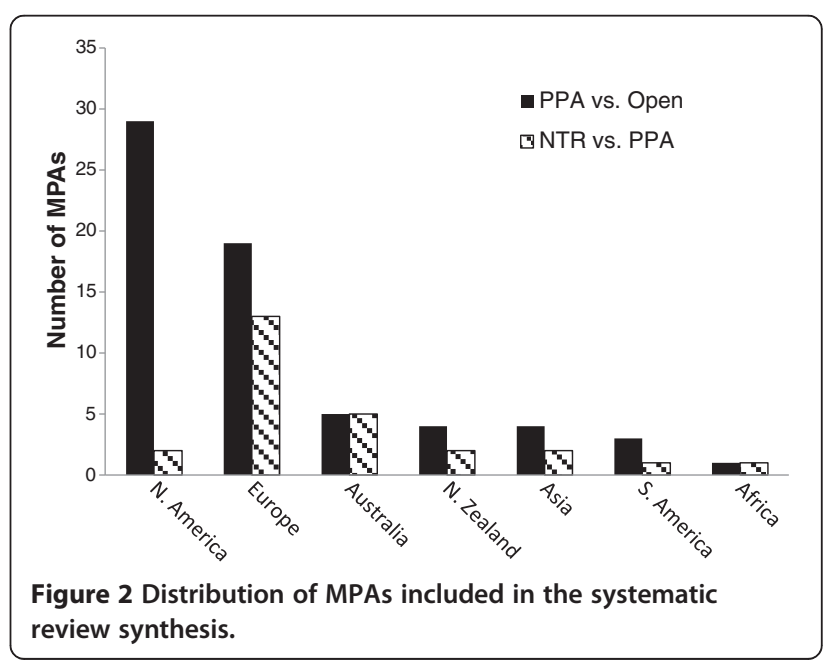




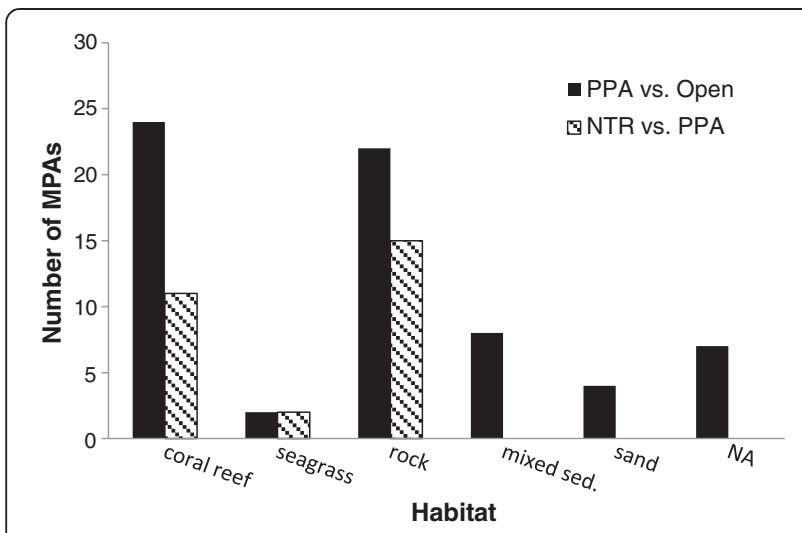

Figure 3 Distribution of habitat types for the MPA case-studies included in the systematic review synthesis.

MPAs presented before-after data. Most studies were based on underwater visual transects (fish studies: 75\%, $\mathrm{n}=38$; invertebrate studies: $48 \%, \mathrm{n}=12$ ). Experimental trawl hauls were the second most common method used for fish studies $(18 \%, \mathrm{n}=9)$, whereas point count methods that included techniques like baited pots, grabs and photographic techniques were the second most common method $(36 \%, \mathrm{n}=9)$ for invertebrate studies. The full details on PPA characteristics, survey design and methodology, and taxa (fish, invertebrate) and metrics (density, biomass, length, species richness) measured for each PPA are given in Tables $1 \mathrm{a}$ and $1 \mathrm{~b}$ in Additional file 5.

\section{Description of studies used in NTR vs. PPA analysis}

The majority of MPAs (50\%) were based in Europe, the remaining MPAs were mainly found in Australia and New Zealand (27\%) (Figure 2). These MPAs were commonly characterized by a zonation scheme, consisting of a no-take area where all extractive activities are prohibited and an adjacent buffer zone or partially protected area where some but not all extractive activities are prohibited. MPA age at the time of study ranged between 2 and 25 years. The size of the NTR ranged between 0.13 and $74 \mathrm{~km}^{2}$ and that for the PPA between 4.5 and $609.95 \mathrm{~km}^{2} .44 \%(\mathrm{n}=8)$ of the studies for which the area of the NTR and the PPA were available, the size of the NTR was less than $10 \%$ that of the PPA. The NTR was larger than the PPA for only 2 MPAs. All studies were conducted on coral reefs, seagrass meadows or rocky reefs (Figure 3). In total, 20 MPAs provided data on fish species, and 14 MPAs for invertebrate species. Density and biomass were the most common measures for assessment of protection on fish, whereas density was most studied for invertebrate populations (Figure 4B). The majority of MPAs were based on after controlimpact studies sampled only once $(31 \%, \mathrm{n}=10)$ or on multiple occasions $(59 \%, \mathrm{n}=19)$. BACI data were presented only for 2 MPAs. Most studies were based on underwater visual transects (fish studies: 63\%, $\mathrm{n}=15$; invertebrate studies: $69 \%, \mathrm{n}=9$ ), the remaining studies used point count methods such as stationary UVC, quadrats and baited underwater video camera. The full details on MPA characteristics, survey design and methodology, and taxa (fish, invertebrate) and metrics (density, biomass, length, species richness) measured for each MPA are given in Tables $2 \mathrm{a}$ and $2 \mathrm{~b}$ in Additional file 5 .

\section{Quantitative synthesis / Meta-analysis}

MPA-level analyses: Comparison of partial protection vs. no protection

Fish density and biomass Overall, fish density and biomass were significantly higher inside the PPA than in the Open area. Fish density was on average 1.4 times higher within PPA boundaries (weighted summary effect size, $\overline{\operatorname{LnRR}}=0.33$, confidence interval $(\mathrm{CI})=0.04 \rightarrow 0.63)$ and biomass was 1.54 times greater in PPA than in open access areas $(\overline{L n R R}=0.43, \mathrm{CI}=0.26 \rightarrow 0.61)$. However, when the analysis was repeated excluding studies that reported an effect of habitat on the assessment of PPA efficacy (4/21
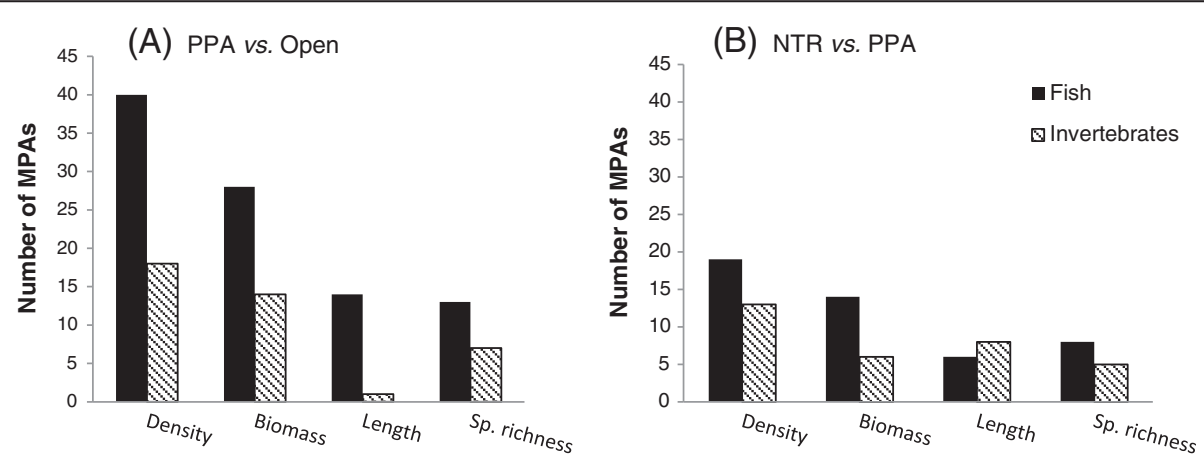

Figure 4 Distribution of outcomes measured for fish and invertebrate species for the studies comparing (A) a partially protected area to an open access area (PPA vs. Open) and (B) a no-take reserve to a partially protected area (NTR vs. PPA). 
for density, Figure 5; 3/21 for biomass, Figure 6), the effect size for fish density was reduced from 1.4 to 1.22 times higher inside the PPA and was barely significant $(\overline{\operatorname{LnRR}}=$ $0 \cdot 22, \mathrm{CI}=0.02 \rightarrow 0.39$ ). This indicates a weaker overall response of density to protection when only those MPAs with no habitat confounding effect were taken into account. On the other hand, the overall response for fish biomass did not change $(\overline{L n R R}=0.41, \mathrm{CI}=0.21 \rightarrow 0.61)$ when the 'habitat-confounded' studies were removed. The prediction interval indicated a large range of effect sizes (Prediction interval (PI) for density $=-0.89 \rightarrow 1.57$, Figure 5; PI for biomass $=-0.15 \rightarrow 1.02$, Figure 6). Hence, the meta-analysis suggests that in general PPAs increase fish density and biomass compared to Open areas but, there is a $29 \%$ and $19 \%$ possibility of finding lower fish density and biomass, respectively, in the PPA relative to the Open area.

There was significant heterogeneity in the response of fish assemblages to protection among PPAs in our datasets (density: $\mathrm{Q}=893.68, \mathrm{df}=20, \mathrm{p}<0.0001$; biomass: $\mathrm{Q}=81.87, \mathrm{df}=20, \mathrm{p}<0.0001$ ) (Figure 5, Figure 6). Several potential effect modifiers were tested in an attempt to explain the variability in effect sizes between studies.

To examine whether the response to protection was influenced by the type of fishing activities prohibited and permitted within the PPA, we conducted a categorical meta-analysis for the effect of 'protection regime' on fish assemblage. Of the six comparisons between PPAs and Open areas (three types of protection regime for each of density and biomass) only one (biomass for the 'discriminate, commercial' DC category) showed significantly higher biomass inside the PPA relative to the Open area (Figure 7). Comparison of the response to partial protection among the three protection regime categories examined was not significantly different for fish assemblage density (sensitivity analysis: $\mathrm{Q}_{\mathrm{M}}=0.63, \mathrm{df}=3, \mathrm{p}=0.73$ ) or biomass (sensitivity analysis: $\mathrm{Q}_{\mathrm{M}}=2.01, \mathrm{df}=3, \mathrm{p}=0.37$ ). We emphasize however, that the results for this effect

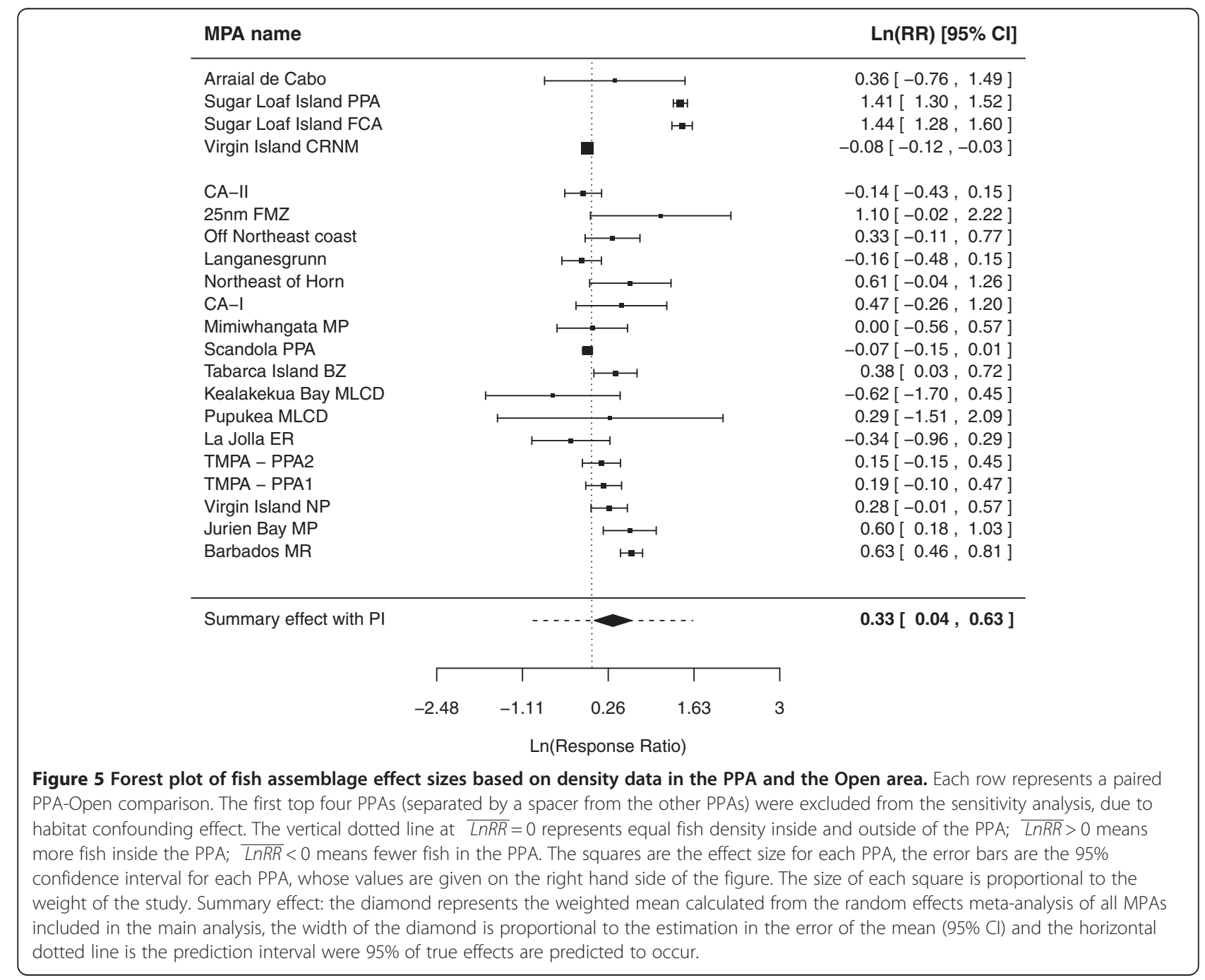




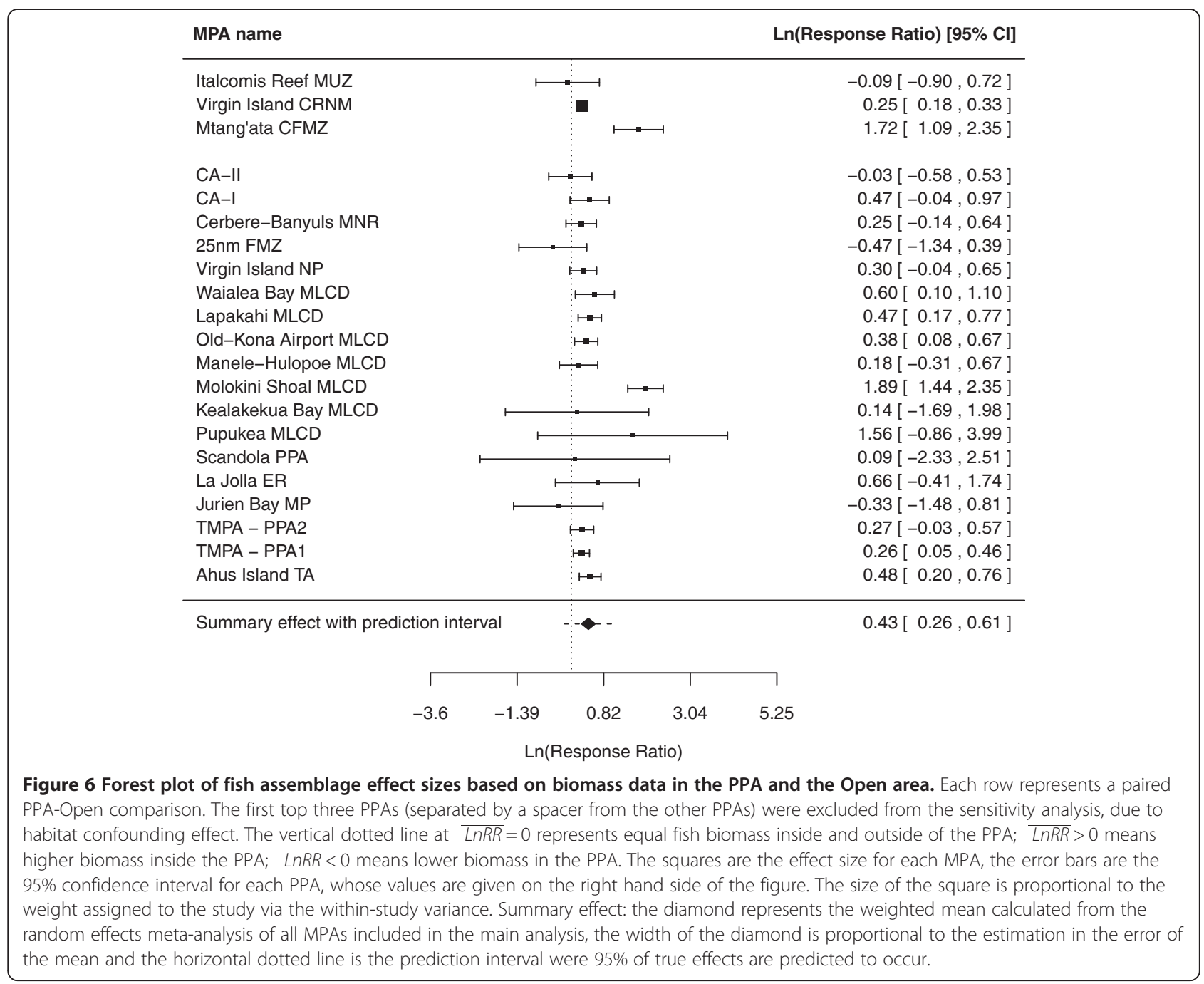

modifier on fish assemblage data should be interpreted with caution owing to the small number of PPA case-studies within each category, which reduces the robustness of the average effect size.

MPA age and the size of the PPA were not significantly related to the effect size for fish assemblage density (Table 2). The difference in the survey methodology represented here by the total area surveyed was not a significant effect modifier (Table 2). A positive significant relationship was found between effect size and the distance of the control area from the PPA boundary (Table 2), which suggested a $28 \%$ increase in effect size for every $1 \mathrm{~km}$ increase in distance between the control area and the PPA. However this relationship became non-significant when the analysis was repeated excluding the habitat-confounded PPAs (Table 2).

The response to protection for fish assemblage biomass was found to be negatively correlated to the size of the PPA, such that effect size (partial:open) decreased by $17 \%$ for every ten-fold increase in PPA size (slope of regression of $\operatorname{Ln}(\mathrm{RR})$ on $\log$ size of $\mathrm{PPA}=-0.17$; $\mathrm{SE}=0.06, \mathrm{p}=0.009)$ (Table 3). The relationship was still significant when 'habitat-confounded' studies were removed from the analysis. None of the other effect modifiers (i.e. PPA age, census area, distance to PPA) explained any of the between-study variability for fish assemblage biomass when 'habitat-confounded' studies were excluded (Table 3).

Fish diversity The average effect of partial protection on fish species richness was not significantly different from zero $(\mathrm{D}=2.08, \mathrm{CI}=-3.54 \rightarrow 7.69)$, and this effect was homogeneous among the included studies $(\mathrm{Q}=0.88, \mathrm{df}=9$, $\mathrm{p}=0.99$ ).

Invertebrates: density, biomass, diversity The small number of studies investigating the effectiveness of PPAs relative to Open areas precluded us from examining the influence of protection on invertebrate assemblages (density: 


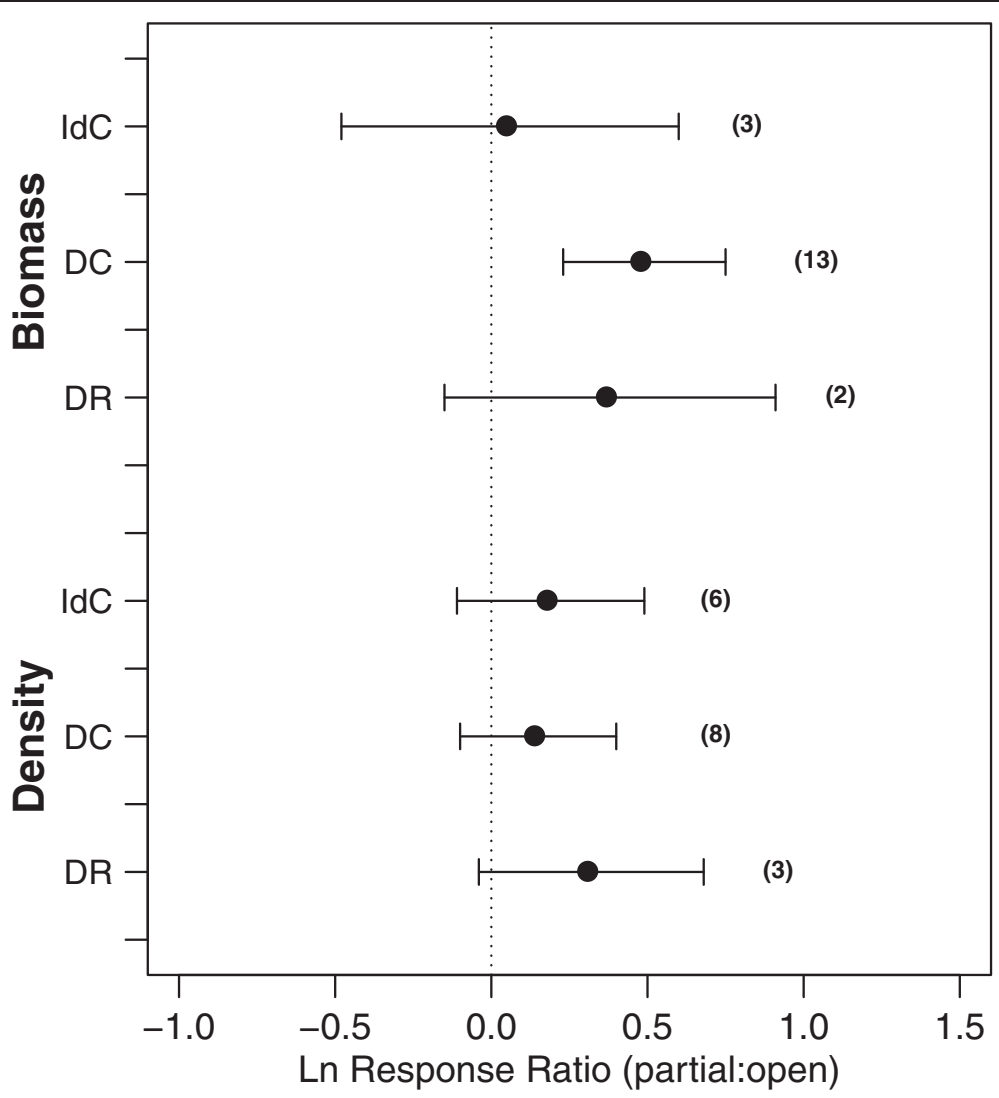

Figure 7 Mean response ratio $(\overline{L n R} R)$ based on density and biomass data in the partially protected area and the open access area (partial:open) for each 'protection regime' category (IdC: Indiscriminate, commercial; DC: discriminate, commercial; DR: discriminate, recreational). Results are shown for the entire fish assemblage. Sample size (i.e. the number of MPAs) for each ratio is shown in parentheses. The vertical dotted line at $(\overline{\operatorname{LnRR}})=0$ represents equal fish density or biomass inside and outside of the PPA; $(\overline{\operatorname{LnRR}})>0$ means more fish inside the

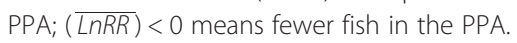

5 studies; biomass: 4 studies; species number: 5 studies) (see Additional file 5 for a list of these studies).

\section{MPA-level analyses: Comparison of full vs. partial protection}

Fish density and biomass Fish assemblage density was on average 1.11 times higher in NTRs relative to PPAs, but the difference was not significant, whether the 'habitatconfounded' studies were removed from the full dataset or not (main analysis: $\overline{L n R R}=0.1, C I=-0.15-0.36$ ) (Figure 8). Conversely, fish assemblage biomass was on average 1.92 times higher in NTRs than PPAs $(\overline{\operatorname{LnRR}}=$ $0.65, \mathrm{CI}=0.25 \rightarrow 1.06$ ) (Figure 9), even when the 'habitatconfounded' study was excluded. The prediction interval

Table 2 Summary of the weighted simple random-effects regression models for each of the four moderator variables on fish assemblage density effect size

\begin{tabular}{|c|c|c|c|}
\hline \multicolumn{4}{|c|}{ All MPA case-studies included } \\
\hline Moderator variable & $\mathrm{N}^{\circ}$ MPAs & Slope $[95 \% \mathrm{Cl}]$ & $Q_{M}, p-v a l$ \\
\hline MPA age (year) & 21 & $-0.001[-0.03 \rightarrow 0.03]$ & $Q_{M}=0.007, p=0.94$ \\
\hline $\log _{10}(\operatorname{size})\left(\mathrm{km}^{2}\right)$ & 21 & $-0.002[-0.24 \rightarrow 0.23]$ & $Q_{M}=0.0004, p=0.98$ \\
\hline $\log _{10}$ (census area) $\left(m^{2}\right)$ & 19 & $-0.005[-0.31 \rightarrow 0.30]$ & $\mathrm{Q}_{\mathrm{M}}=0.001, \mathrm{p}=0.97$ \\
\hline Min. Distance $(\mathrm{km})$ & 19 & $0.28[0.18 \rightarrow 0.37]$ & $\mathrm{Q}_{\mathrm{M}}=31.59, \mathrm{p}<0.0001$ \\
\hline \multicolumn{4}{|c|}{ Sensitivity analysis; habitat confounded studies excluded } \\
\hline Min. Distance $(\mathrm{km})$ & 15 & $-0.23[-0.65 \rightarrow 0.19]$ & $Q_{M}=1.17, p=0.28$ \\
\hline
\end{tabular}

Data under sensitivity analysis is given only for the moderator variable which showed a considerably different result from when all studies were included. 
Table 3 Summary of the weighted simple random-effects regression models for each of the four moderator variables on fish assemblage biomass effect size

\begin{tabular}{|c|c|c|c|}
\hline \multicolumn{4}{|c|}{ All MPA case-studies included } \\
\hline Moderator variable & $\mathrm{N}^{\circ}$ MPAs & Slope $[95 \% \mathrm{Cl}]$ & $Q_{M}, p$-val \\
\hline MPA age (year) & 21 & $0.004[-0.007 \rightarrow 0.02]$ & $Q_{M}=0.49, p=0.49$ \\
\hline $\log _{10}(\operatorname{size})\left(\mathrm{km}^{2}\right)$ & 20 & $-0.17[-0.27 \rightarrow 0.06]$ & $Q_{M}=9.28, p=0.002$ \\
\hline $\log _{10}\left(\right.$ census area) $\left(m^{2}\right)$ & 18 & $-0.26[-0.52 \rightarrow 0.004]$ & $Q_{M}=3.73, p=0.05$ \\
\hline Min. Distance $(\mathrm{km})$ & 18 & $0.05[0.02 \rightarrow 0.09]$ & $Q_{M}=11.59, p=0.0007$ \\
\hline \multicolumn{4}{|c|}{ Sensitivity analysis; habitat confounded studies excluded } \\
\hline $\log _{10}($ size $)\left(\mathrm{km}^{2}\right)$ & 18 & $-0.17[-0.29 \rightarrow-0.04]$ & $Q_{M}=6.78, p=0.01$ \\
\hline $\log _{10}\left(\right.$ census area) $\left(\mathrm{m}^{2}\right)$ & 15 & $-0.24[-0.51 \rightarrow 0.03]$ & $\mathrm{Q}_{M}=3.13, p=0.08$ \\
\hline Min. Distance $(\mathrm{km})$ & 15 & $-0.13[-0.31 \rightarrow 0.06]$ & $Q_{M}=1.82, p=0.18$ \\
\hline
\end{tabular}

Data under sensitivity analysis is given only for the moderator variable which showed considerable different result from when all studies were included.

for both measures overlapped zero (Prediction interval (PI) for density $=-0.27 \rightarrow 0.27$, Figure 8 ; PI for biomass $=$ $-0.12 \rightarrow 1.42$, Figure 9) and suggest that a new MPA might have lower or higher density inside the NTR than in the PPA. Fish biomass, however, may show an increase inside the NTR relative to the PPA by as much as 4 times.

Between-study heterogeneity was significant for fish density $(\mathrm{Q}=98.62, \mathrm{df}=8, \mathrm{p}<0.0001)$, as well as for biomass $(\mathrm{Q}=20.83, \mathrm{df}=5, \mathrm{p}=0.0009)$. However, the

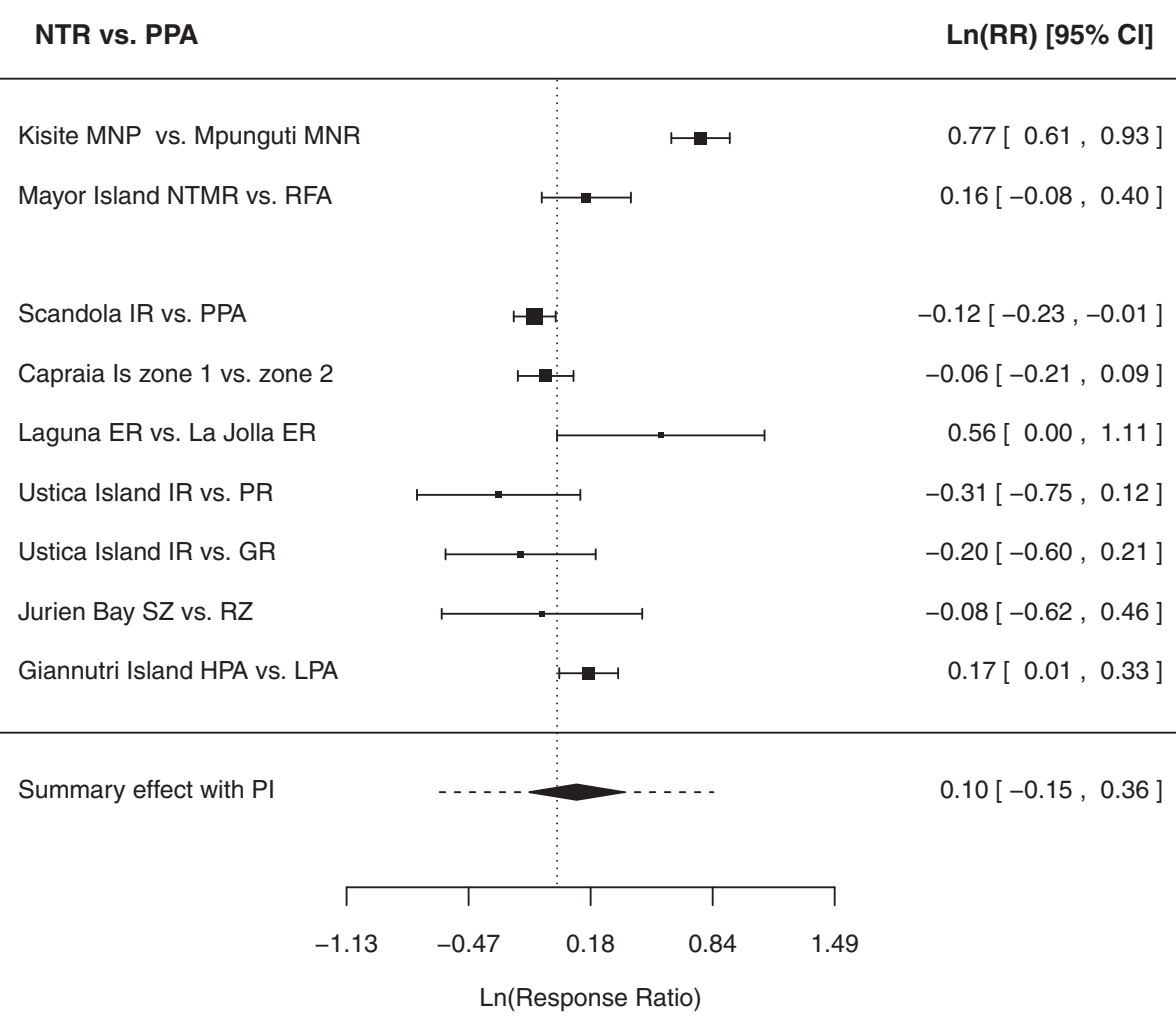

Figure 8 Forest plot of fish population effect sizes based on density data in the NTR and the PPA. Each row represents a paired NTR-PPA comparison. The top two MPAs (separated by a spacer from the other MPAs) were excluded from the sensitivity analysis, due to habitat

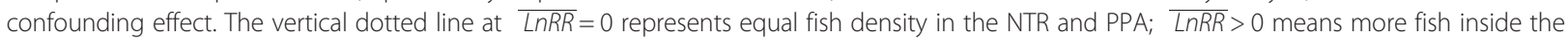
NTR; $\overline{L n R R}<0$ means fewer fish in the NTR. The squares are the effect size for each MPA, the error bars are the 95\% confidence interval for each MPA, whose values are given on the right hand side of the figure. Summary effect: the diamond represents the weighted mean calculated from the random effects meta-analysis, the width of the diamond is proportional to the estimation in the error of the mean and the horizontal dotted line is the prediction interval were $95 \%$ of true effects are predicted to lie. 


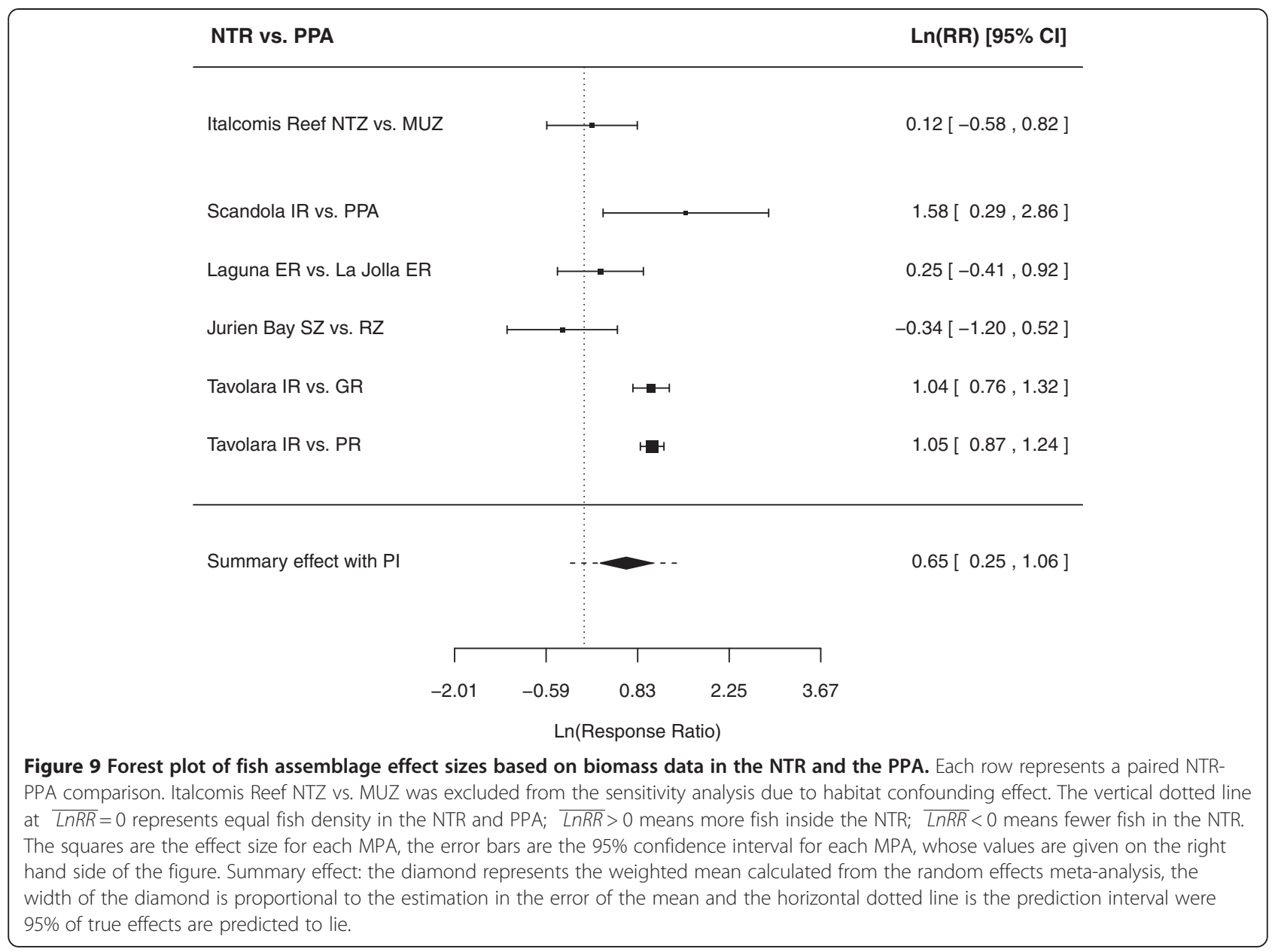

small number of studies (9 for density and 6 for biomass) precluded further meta-analysis for examining the effect of MPA age, the size ratio of the NTR to the PPA and the distance between the NTR and PPA on the response of fish assemblages to full protection.

Fish diversity The average effect of full over partial protection on fish species richness was not significantly different from zero $(\mathrm{D}=-0.45, \mathrm{CI}=-2.81 \rightarrow 1.91)$, and this effect was homogeneous among the included studies $(\mathrm{Q}=1.88$, $\mathrm{df}=8, \mathrm{p}=0.97$ ).

Invertebrates: density, biomass, diversity The small number of studies investigating the effectiveness of NTRs relative to PPAs precluded us from examining the influence of full protection on invertebrate assemblages (density: 1 study; biomass: 0; species richness: 3 studies).

\section{Species-level analysis: Comparison of partial protection vs.} no protection

Fish density and biomass Target and non-target fish species had significantly higher density inside PPAs than in Open areas (Table 4a, note that all CIs are greater than zero). However, when the analysis was repeated excluding habitat-confounded' studies, there was no significant effect of protection for non-target species (Table 4b, note that CI for non-target species overlaps zero). In terms of biomass, the response for TP species was on average 1.5 times higher inside the PPA than outside, whereas that of TNP and NT species did not differ significantly inside and outside of the PPA (Table 5). When the analyses were re-run under different scenarios of correlation coefficients among species (rho $=0,0.2,0.5,0.8,1)$ similar trends for the direction of protection effect were obtained, in spite of some differences in the magnitude of effect for TNP and NT categories (Tables 4, 5).

In spite of some significant differences in density and biomass between the protected and open access areas, the magnitude of response to protection was not significantly different among the three 'exploitation status' categories (TP, TNP, NT) (sensitivity analysis for density: $\mathrm{Q}_{\mathrm{M}}=3.98, \mathrm{df}=2, \mathrm{p}=0.14$; sensitivity analysis for biomass: $\mathrm{Q}_{\mathrm{M}}=0.15, \mathrm{df}=2, \mathrm{p}=0.93$ ). To minimize the ecological and performance biases across different studies, we calculated a second effect size $\left(E S_{D I F F}\right)$ that consisted 
Table 4 The response to protection ( $\overline{\operatorname{LnRR}}[95 \% \mathrm{CI}]$ ) for each 'exploitation status' category (target-protected [TP], target-not protected [TNP] and non-target [NT]), using density data

\begin{tabular}{|c|c|c|c|c|c|c|}
\hline & \multicolumn{3}{|c|}{ (a) All MPA case-studies included } & \multicolumn{3}{|c|}{ (b) Sensitivity analysis; habitat confounded studies excluded } \\
\hline & TP & TNP & NT & TP & TNP & NT \\
\hline & $N=29$ & $\mathrm{~N}=5$ & $\mathrm{~N}=10$ & $N=27$ & $\mathrm{~N}=5$ & $N=8$ \\
\hline rho $=0$ & $0.47[0.22 \rightarrow 0.72]$ & $0.78[0.18 \rightarrow 1.38]$ & $0.57[0.17 \rightarrow 0.97]$ & $0.41[0.21 \rightarrow 0.61]$ & $0.76[0.30 \rightarrow 1.22]$ & $0.21[-0.12 \rightarrow 0.54]$ \\
\hline rho $=0.2$ & $0.47[0.21 \rightarrow 0.73]$ & $0.81[0.17 \rightarrow 1.46]$ & $0.59[0.16 \rightarrow 1.04]$ & $0.41[0.20 \rightarrow 0.61]$ & $0.80[0.32 \rightarrow 1.28]$ & $0.19[-0.19 \rightarrow 0.56]$ \\
\hline rho $=0.5$ & $0.47[0.20 \rightarrow 0.74]$ & $0.85[0.17 \rightarrow 1.52]$ & $0.64[0.17 \rightarrow 1.12]$ & $0.41[0.20 \rightarrow 0.62]$ & $0.85[0.34 \rightarrow 1.35]$ & $0.18[-0.23 \rightarrow 0.60]$ \\
\hline rho $=0.8$ & $0.47[0.20 \rightarrow 0.75]$ & $0.87[0.17 \rightarrow 1.57]$ & $0.68[0.18 \rightarrow 1.17]$ & $0.41[0.20 \rightarrow 0.63]$ & $0.88[0.36 \rightarrow 1.41]$ & $0.19[-0.26 \rightarrow 0.63]$ \\
\hline rho $=1$ & $0.47[0.19 \rightarrow 0.75]$ & $0.89[0.18 \rightarrow 1.60]$ & $0.70[0.20 \rightarrow 1.20]$ & $0.41[0.20 \rightarrow 0.63]$ & $0.90[0.36 \rightarrow 1.44]$ & $0.19[-0.27 \rightarrow 0.65]$ \\
\hline
\end{tabular}

Results where different correlation coefficients (rho $=0,0.2,0.5,0.8,1$ ) among individual species responses were used to compute the within-study sampling variance are given on separate rows. The summary effect size and $95 \% \mathrm{Cl}$ are given for analysis using (a) all PPA case-studies, and (b) excluding PPAs with habitat confounded effects. $\mathrm{N}$ represents the number of PPAs for each exploitation category. $\overline{L n R R}>0$ means more fish inside the PPA; $\operatorname{LnRR}<0$ means fewer fish in the PPA. When the $\mathrm{Cl}$ overlaps 0 it implies a non-significant difference between PPA and non-protected area.

Table 5 The response to protection ( $\overline{L n R R}$, [95\% CI]) for each 'exploitation status' category (target-protected [TP], target-not protected [TNP] and non-target [NT]), using biomass data

\begin{tabular}{|c|c|c|c|c|c|c|}
\hline & \multicolumn{3}{|c|}{ (a) All MPA case-studies included } & \multicolumn{3}{|c|}{ (b) Sensitivity analysis; habitat confounded studies excluded } \\
\hline & TP & TNP & NT & TP & TNP & NT \\
\hline & $N=12$ & $N=5$ & $N=7$ & $N=10$ & $N=5$ & $N=6$ \\
\hline rho $=0$ & $0.35[0.12 \rightarrow 0.59]$ & $0.43[0.07 \rightarrow 0.79]$ & $0.18[-0.14 \rightarrow 0.50]$ & $0.42[0.18 \rightarrow 0.67]$ & $0.43[0.07 \rightarrow 0.79]$ & $0.23[-0.10 \rightarrow 0.56]$ \\
\hline rho $=0.2$ & $0.38[0.12 \rightarrow 0.64]$ & $0.42[0.03 \rightarrow 0.80]$ & $0.22[-0.16 \rightarrow 0.60]$ & $0.44[0.17 \rightarrow 0.71]$ & $0.42[0.04 \rightarrow 0.80]$ & $0.29[-0.11 \rightarrow 0.69]$ \\
\hline rho $=0.5$ & $0.40[0.11 \rightarrow 0.69]$ & $0.40[-0.02 \rightarrow 0.82]$ & $0.26[-0.17 \rightarrow 0.68]$ & $0.45[0.15 \rightarrow 0.76]$ & $0.40[-0.02 \rightarrow 0.81]$ & $0.35[-0.10 \rightarrow 0.80]$ \\
\hline rho $=0.8$ & $0.40[0.09 \rightarrow 0.72]$ & $0.38[-0.07 \rightarrow 0.82]$ & $0.28[-0.18 \rightarrow 0.74]$ & $0.46[0.13 \rightarrow 0.80]$ & $0.38[-0.06 \rightarrow 0.82]$ & $0.39[-0.10 \rightarrow 0.88]$ \\
\hline rho $=1$ & $0.41[0.08 \rightarrow 0.74]$ & $0.37[-0.09 \rightarrow 0.83]$ & $0.29[-0.18 \rightarrow 0.77]$ & $0.47[0.12 \rightarrow 0.82]$ & $0.37[-0.09 \rightarrow 0.82]$ & $0.41[-0.10 \rightarrow 0.92]$ \\
\hline
\end{tabular}

Results where different correlation coefficients ( $r$ o $=0,0.2,0.5,0.8,1$ ) among individual species responses were used to compute the within-study sampling variance are given on separate rows. The summary effect size and $95 \% \mathrm{Cl}$ are given for analysis using (a) all PPA case-studies, and (b) excluding PPAs with habitat confounded effects. $\mathrm{N}$ represents the number of PPAs for each exploitation category. $\operatorname{Ln}(\mathrm{RR})>0$ means more fish inside the PPA; Ln(RR) $<0$ means fewer fish in the PPA. When the $\mathrm{Cl}$ overlaps 0 it implies a non-significant difference between PPA and non-protected area.

Table 6 The difference in the magnitude of response to protection (ES $S_{\text {DIFF }}$ ) between target-protected [TP] and nontarget [NT] species for density data

\begin{tabular}{|c|c|c|c|c|c|c|c|c|}
\hline & \multicolumn{4}{|c|}{ (a) All MPA case-studies included $(\mathrm{N}=9)$} & \multicolumn{4}{|c|}{ (b) Sensitivity analysis; habitat confounded studies excluded ( $N=7$ ) } \\
\hline & $\mathrm{ES}_{\mathrm{DIFF}}$ & $95 \% \mathrm{Cl}$ & Z-val & p-val & $\mathrm{ES}_{\mathrm{DIFF}}$ & $95 \% \mathrm{Cl}$ & Z-val & p-val \\
\hline rho $=0$ & -0.32 & $-0.72 \rightarrow 0.08$ & -1.55 & 0.12 & -0.09 & $-0.37 \rightarrow 0.19$ & -0.64 & 0.52 \\
\hline rho $=0.5$ & -0.29 & $-0.69 \rightarrow 0.11$ & -1.42 & 0.15 & -0.08 & $-0.37 \rightarrow 0.22$ & -0.52 & 0.60 \\
\hline rho $=1$ & -0.25 & $-0.56 \rightarrow 0.06$ & -1.60 & 0.11 & -0.03 & $-0.28 \rightarrow 0.22$ & -0.23 & 0.82 \\
\hline
\end{tabular}

Studies were weighted by the variance of the difference between two correlated variables (correlation coefficients of rho $=0,0.5,1$ ). The $\mathrm{ES}_{\mathrm{DIFF}}, 95 \%$ confidence interval, Z-val and p-val are given for (a) all PPA case-studies that provided data for both categories and (b) for PPAs with no habitat confounded effect. N represents the number of PPAs included in the analysis.

Table 7 The difference in the magnitude of response to protection (ES DIFF between target-protected and non-target species for biomass data

\begin{tabular}{|c|c|c|c|c|c|c|c|c|}
\hline & \multicolumn{4}{|c|}{ (a) All MPA case-studies included $(\mathrm{N}=6)$} & \multicolumn{4}{|c|}{ (b) Sensitivity analysis; habitat confounded studies excluded ( $N=5$ ) } \\
\hline & $\mathrm{ES}_{\mathrm{DIFF}}$ & $95 \% \mathrm{Cl}$ & Z-val & p-val & $\mathrm{ES}_{\text {DIFF }}$ & $95 \% \mathrm{Cl}$ & Z-val & p-val \\
\hline rho $=0$ & 0.04 & $-0.56 \rightarrow 0.64$ & 0.13 & 0.89 & 0.008 & $-0.67 \rightarrow 0.69$ & 0.02 & 0.98 \\
\hline rho $=0.5$ & 0.13 & $-0.48 \rightarrow 0.74$ & 0.41 & 0.67 & 0.10 & $-0.60 \rightarrow 0.80$ & 0.27 & 0.79 \\
\hline rho $=1$ & 0.19 & $-0.15 \rightarrow 0.53$ & 1.09 & 0.27 & 0.16 & $-0.23 \rightarrow 0.55$ & 0.81 & 0.42 \\
\hline
\end{tabular}

Studies were weighted by the variance of the difference between two correlated variables (correlation coefficients of rho $=0,0.5,1$ ). The $\mathrm{ES}_{\mathrm{DIFF}}, 95 \%$ confidence interval, Z-val and p-val are given for (a) all PPA case-studies that provide data for both categories and (b) for PPAs with no habitat confounded effect. N represents the number of PPAs included in the analysis. 


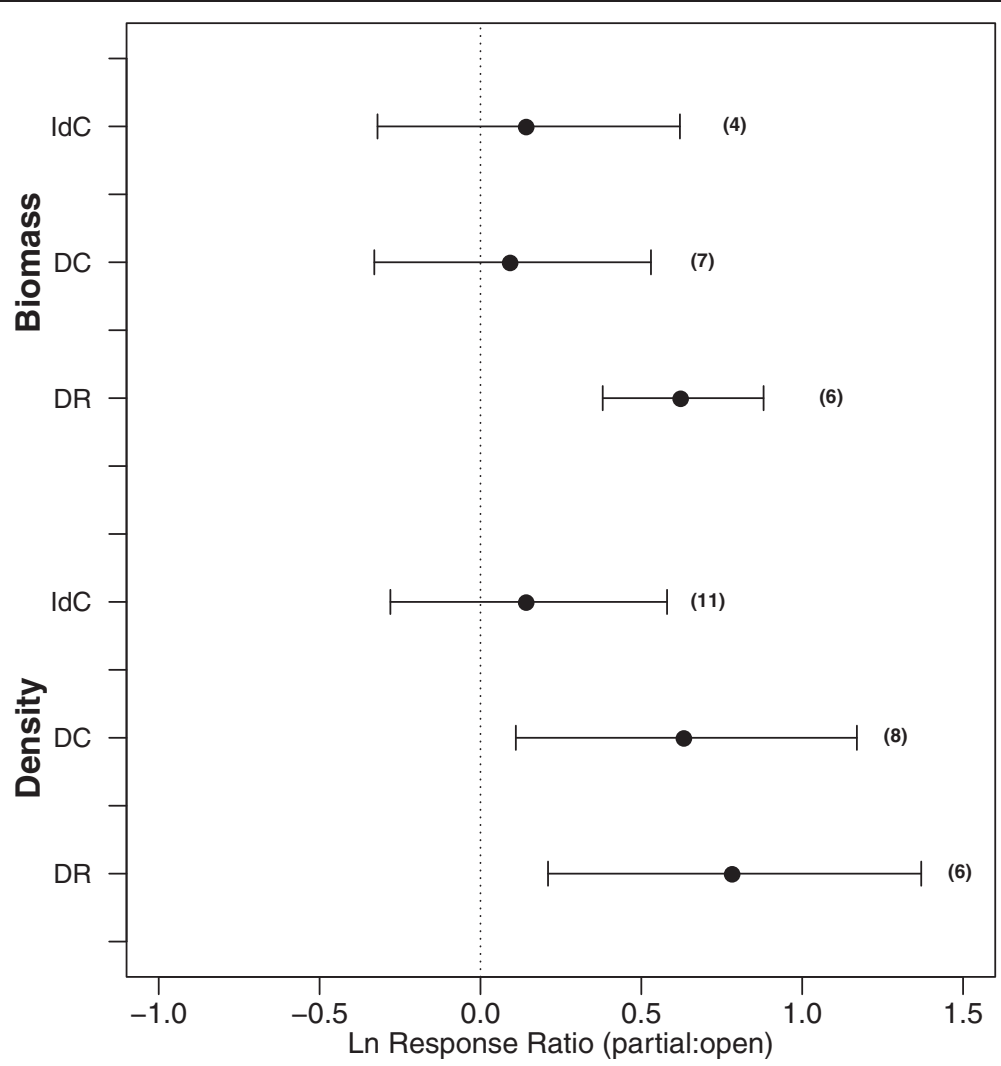

Figure 10 Mean response ratio ( $\overline{L n R R}$ ) based on density and biomass data for target species in the partially protected area and the open access area (partial:open) for each 'protection regime' category (IdC: Indiscriminate, commercial; DC: discriminate, commercial; DR: discriminate, recreational). Sample size (i.e. the number of MPAs) for each ratio is shown in parentheses. The vertical dotted line at $(\overline{L n R R})=0$ represents equal fish density or biomass inside and outside of the MPA; $(\overline{L n R R})>0$ means more fish inside the PPA; $(\overline{L n R R})<0$ means fewer fish in the PPA.

of the difference between the average effect size for two exploitation categories. Given that there were too few studies that reported data for species density and biomass for each of the TNP vs. NT and TP vs. TNP category combinations, the $E S_{D I F F}$ could only be used to compare the magnitude of response to protection between TP and NT species. We did not find significant differences in the magnitude of response to protection between TP and NT species [effect size difference $\left(E S_{\text {DIFF }}\right)$ ranged between -0.03 and -0.09 ] whether density (Table 6) or biomass (Table 7) data were used. This outcome is in agreement with that of the $\mathrm{Q}_{\mathrm{M}}$ statistic above.
There was significant heterogeneity in the response of target fish species to protection among MPAs in our datasets (density: $\mathrm{Q}=112.84, \mathrm{df}=19, \mathrm{p}<0.0001$; biomass: $Q=30.39, \mathrm{df}=12, \mathrm{p}=0.002$ ). Several potential effect modifiers were tested in an attempt to explain the variability in effect sizes between studies. A categorical meta-analysis was conducted to examine if the response of target species to protection was influenced by the protection regime of the PPA. Density and biomass were significantly greater (on average twice as high) in the PPA that allows fishing on a recreational basis or for domestic use only (DR) compared to the Open area

Table 8 Summary of the simple regression models for each of the four moderator variables on target fish biomass

\begin{tabular}{|c|c|c|c|}
\hline \multicolumn{4}{|c|}{ All MPA case-studies included } \\
\hline Moderator variable & $\mathrm{N}^{\circ}$ MPAs & Slope $[95 \% \mathrm{Cl}]$ & $Q_{M}, p-v a l$ \\
\hline MPA age (year) & 16 & $-0.03[-0.06 \rightarrow-0.003]$ & $Q_{M}=4.57, p=0.03$ \\
\hline $\log _{10}($ size $)\left(\mathrm{km}^{2}\right)$ & 17 & $-0.07[-0.25 \rightarrow 0.11]$ & $Q_{M}=0.60, p=0.44$ \\
\hline Min. Distance (km) & 14 & $0.007[-0.05 \rightarrow 0.06]$ & $Q_{M}=0.06, p=0.81$ \\
\hline \# species combined & 16 & $-0.02[-0.09 \rightarrow 0.05]$ & $Q_{M}=0.28, p=0.60$ \\
\hline
\end{tabular}

Similar results were obtained for the sensitivity analysis. 
(density (main analysis): $L n R R_{D R}=0.79, \mathrm{CI}=0.21-1.37$; $\operatorname{Ln} R R_{D C}=0.64, \mathrm{CI}=0.12-1.17 ; \operatorname{LnR} R_{I d C}=0.15, \mathrm{CI}=$ $-0.27-0.58$; Figure 10) (biomass (main analysis): $L n R R_{D R}=0.63, \quad \mathrm{CI}=0.37-0.88 ; \quad \operatorname{LnR} R_{D C}=0.1, \quad \mathrm{CI}=$ $\left.-0.34-0.53 ; \operatorname{LnR} R_{I d C}=0.15, \mathrm{CI}=-0.33-0.62\right)$. Nevertheless, the magnitude of response to protection did not differ significantly among the three protection regimes for target species density $\left(\mathrm{Q}_{\mathrm{M} 2,17}=3.74, \mathrm{p}=0.15\right)$, and was marginally non-significant for target species biomass $\left(\mathrm{Q}_{\mathrm{M} 2,14}=5.89, \mathrm{p}=0.05\right)$.
The biomass of target fish species inside the PPA showed a slight $(\sim 3 \%)$ but significant reduction relative to the open access area upon increasing the duration of protection (slope $=-0.03, \mathrm{CI}=-0.06-0.003$, Table 8, Figure 11). MPA age did not affect target species density (Table 9). The response to protection for target species biomass (Table 8) and density (Table 9) was not related to PPA size. The relationship between effect size and the distance of the open access area to the PPA border was not significant for target species in terms of density or
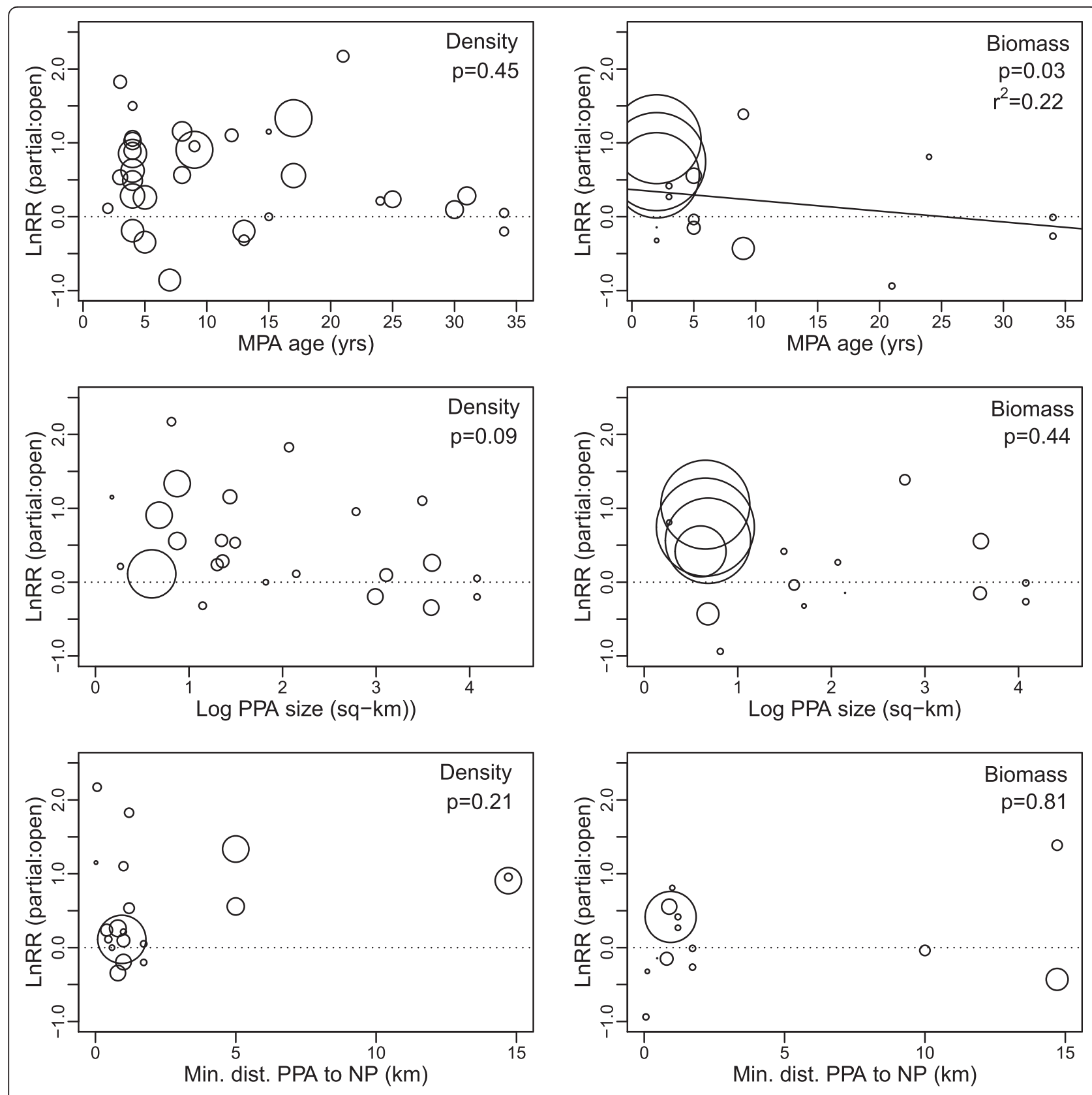

Figure 11 The relationship of target species' response to partial protection (partial:open) with MPA-related parameters (MPA age (yrs), Log PPA size (sq-km), dist). PPA to NP (km) for density and biomass data. Size of the circles is proportional to the weight of the study. 
Table 9 Summary of the simple regression models for each of the four moderator variables examined on target fish density All MPA case-studies included

\begin{tabular}{lcll}
\hline Moderator variable & $\mathbf{N}^{\mathbf{0}}$ MPAs & Slope $[\mathbf{9 5 \%} \mathbf{C l}]$ & $\mathbf{Q}_{\mathbf{M}}, \mathbf{p}$-val \\
\hline MPA age $($ year) & 33 & $-0.01[-0.03 \rightarrow 0.02]$ & $\mathbf{Q}_{\mathbf{M}}=0.57, p=0.45$ \\
$\log _{10}($ size $)\left(\mathrm{km}^{2}\right)$ & 24 & $-0.20[-0.44 \rightarrow 0.03]$ & $\mathrm{Q}_{\mathbf{M}}=2.79, p=0.09$ \\
Min. Distance $(\mathrm{km})$ & 20 & $0.04[-0.02 \rightarrow 0.11]$ & $\mathrm{Q}_{\mathbf{M}}=1.6, p=0.21$ \\
\# species combined & 34 & $-0.04[-0.11 \rightarrow 0.02]$ & $\mathrm{Q}_{\mathbf{M}}=1.67, p=0.20$ \\
\hline
\end{tabular}

Similar results were obtained for the sensitivity analysis.

biomass (Tables 8, 9). The influence of aggregating effect sizes across several species to generate an average effect size for each MPA (represented here by the 'number of species combined') was not significantly related to target species response to protection (Tables 8, 9). Re-running the analysis under scenarios of different correlation coefficients among species $(r h o=0,0.2,0.5,0.8,1)$ gave a similar result, hence only the result for rho $=0.5$ are presented in Tables 8 and 9, and Figure 11.
Fish length The influence of protection on fish body size (i.e. mean length) was only examined for TP species, as the TNP and NT species categories were under-represented in the studies included for this review (see Figure 12). Overall, target species length was not significantly different between the partially protected and the open access areas $(\overline{\operatorname{LnRR}}=0.02,95 \% \mathrm{CI}=-0.04 \rightarrow 0.08$, Figure 12$)$.

There was considerable variability in the response to protection for target fish species among the different

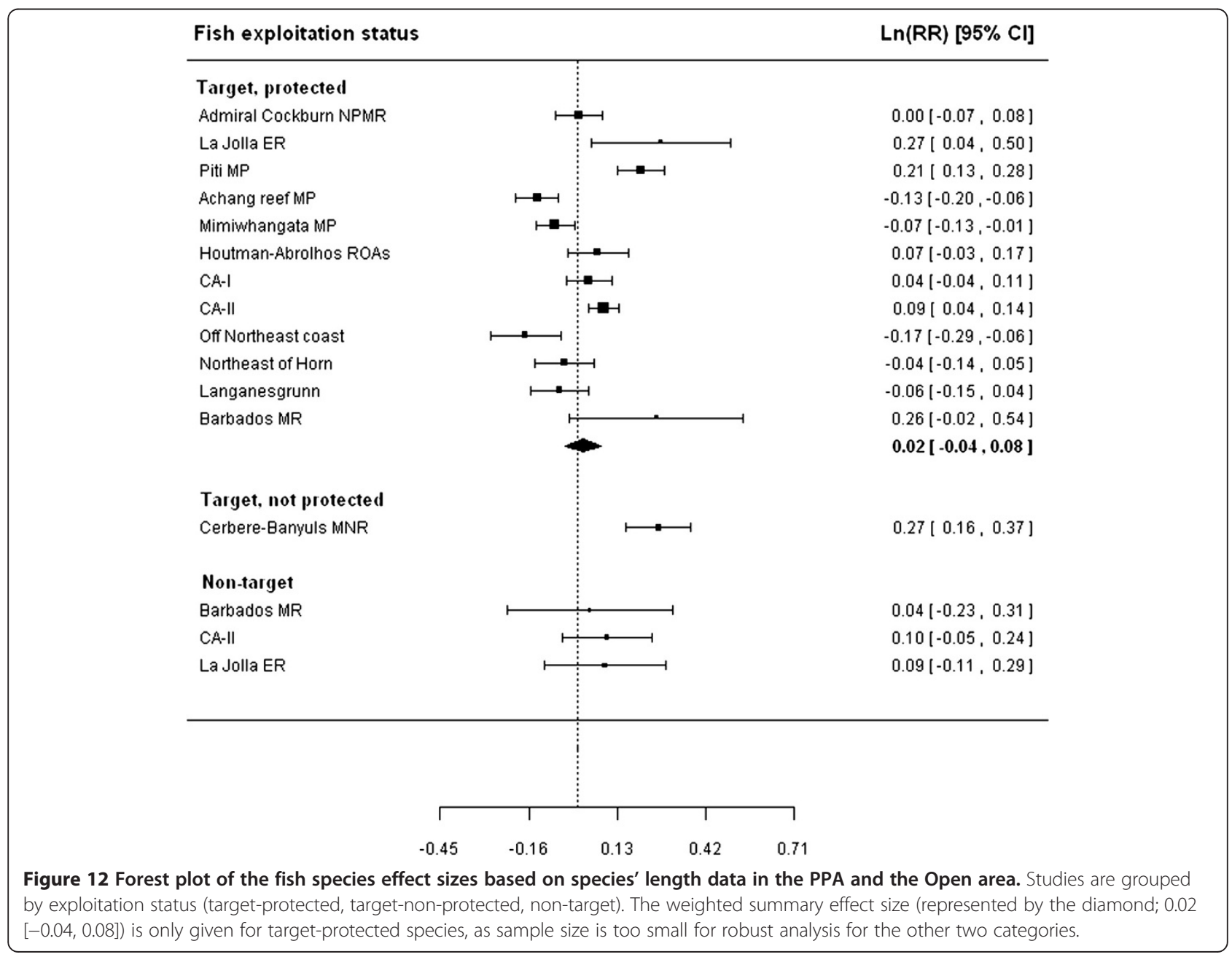


Table 10 Summary of the simple regression models for each of the four moderator variables on target fish length

All MPA case-studies included

\begin{tabular}{lcll}
\hline Moderator variable & $\mathbf{N}^{\mathbf{0}}$ MPAs & Slope $[\mathbf{9 5 \%} \mathrm{Cl}]$ & $\mathbf{Q}_{\mathbf{M}}, \mathbf{p}$-val \\
\hline MPA age $($ year) & 11 & $-0.005[-0.01 \rightarrow 0.004]$ & $\mathrm{Q}_{M}=1.14, p=0.28$ \\
$\log _{10}($ size $)\left(\mathrm{km}^{2}\right)$ & 12 & $-0.03[-0.09 \rightarrow 0.02]$ & $Q_{M}=1.39, p=0.24$ \\
Min. Distance $(\mathrm{km})$ & 12 & $0.02[-0.02 \rightarrow 0.05]$ & $Q_{M}=0.94, p=0.33$ \\
\# species combined & 12 & $0.002[-0.02 \rightarrow 0.02]$ & $Q_{M}=0.04, p=0.84$ \\
\hline
\end{tabular}

Similar results were obtained for the sensitivity analysis.

PPA case-studies $(\mathrm{Q}=80.14, \mathrm{df}=11, \mathrm{p}<0.0001)$. However none of the moderator variables examined (PPA age, size, distance to control, \# of species combined) explained a significant amount of variation in target species length effect sizes among MPAs (Table 10).

Invertebrates: density, biomass, length As the response to protection (partial:open) is likely to be influenced by species characteristics (e.g. growth rate, larval dispersal potential, adult mobility), it would be inadequate to aggregate data across different invertebrate taxonomic groups with very different life history and ecological characteristics. Hence, the effect of protection was examined separately for each taxonomic group. Replication was sufficient only to assess the effect of protection on scallops (class: Bivalvia), lobsters (Class: Decapoda) and sea urchins (class: Echinoidea).

Lobsters and scallops that are targeted by fisheries' outside the PPA, showed a positive response to partial protection, however the response was stronger and more consistent for scallops (Figure 13). In contrast, non-target echinoid species generally had smaller density (Figure 13)

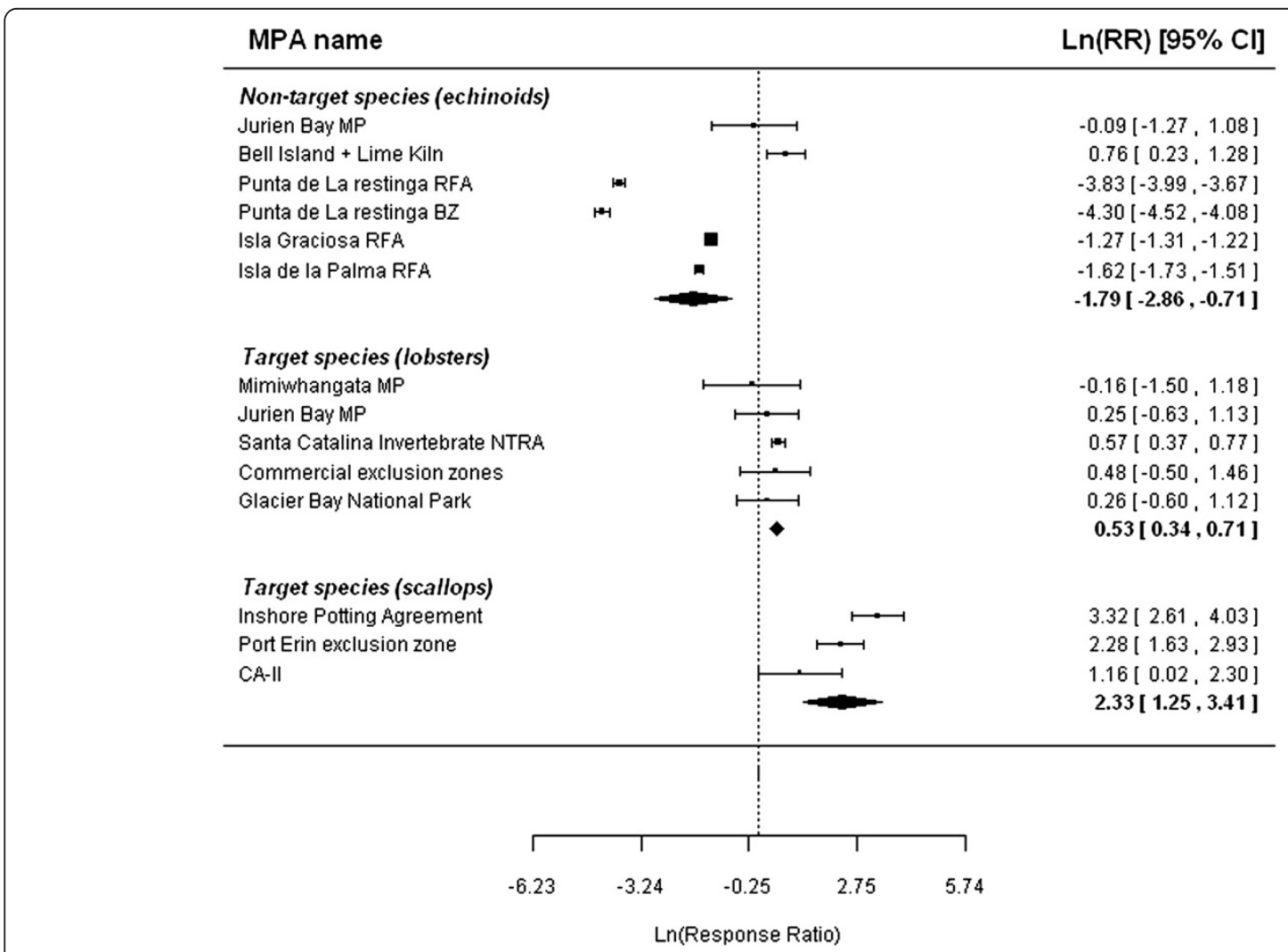

Figure 13 Forest plot of the response ratio (partial:open) of target and non-target invertebrate density categorized by taxonomic class. The vertical dotted line at $\overline{L n R R}=0$ represents equal invertebrate density inside and outside of the PPA. The squares are the effect size for each PPA, the error bars are the $95 \%$ confidence interval, whose values are given on the right hand side of the figure. The overall weighted mean effect is given by the 'Summary effect'. 


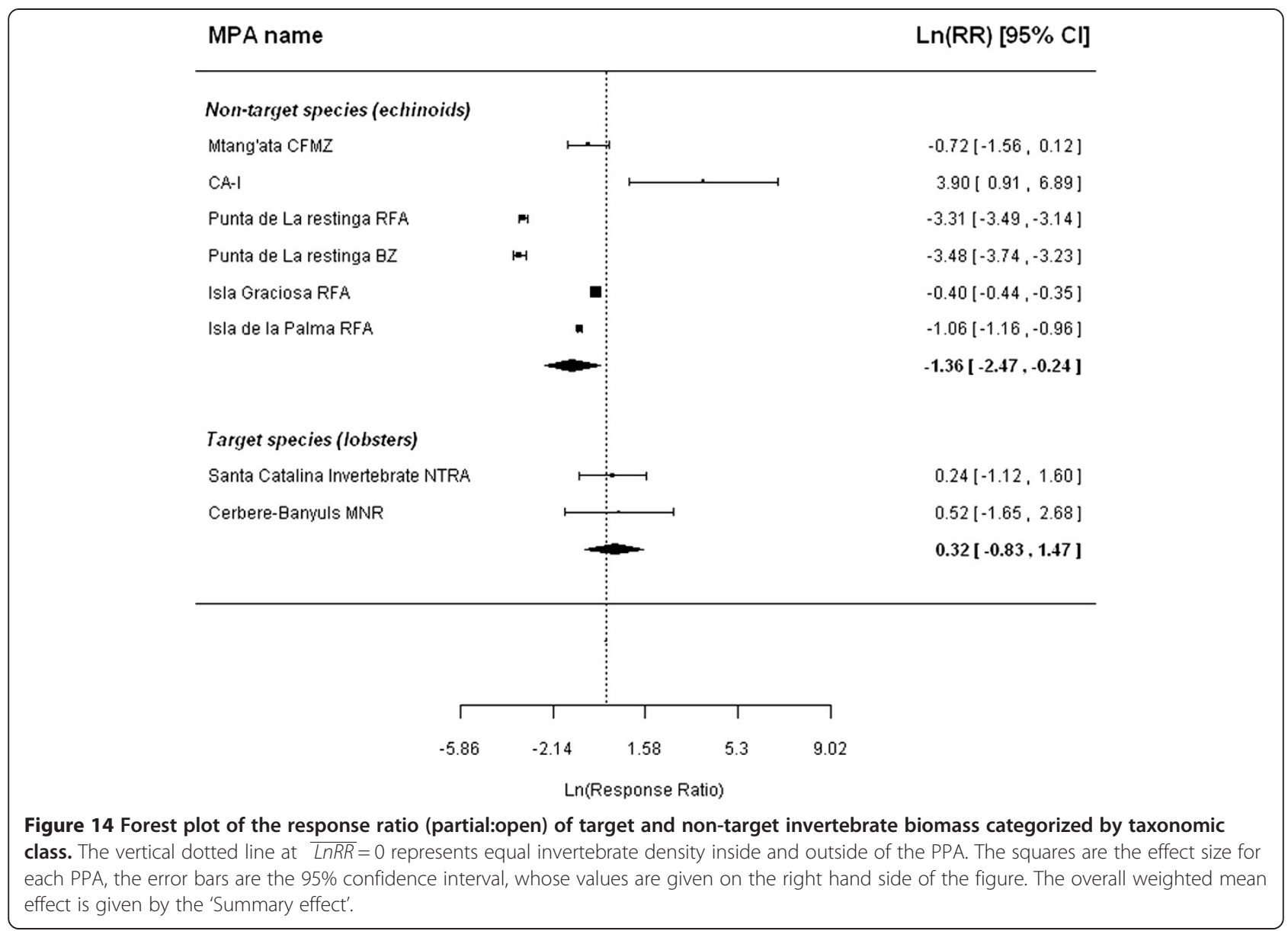

and biomass (Figure 14) in the PPA relative to the Open area. There were too few studies to investigate the effect of protection in terms of species body size (i.e. length).

\section{Species-level analysis: Comparison of full vs. partial protection}

Fish density and biomass On average, the biomass of target species was higher in NTRs than in PPAs, but this increase was only significant for target species that are protected inside the no-take reserve but not in the partially protected area, TNP (Table 11). The effect of protection on non-target species biomass could not be examined due to insufficient data (Table 11). For density, the overall response to full protection was positive for the two target species categories, but negative for non-target species (sensitivity analysis in

Table 11 The summary effect size $\overline{L n R R}$ and [95\% CI] based on biomass data for target-protected [TP] and target-not protected [TNP] exploitation categories, weighted by sampling variances

\begin{tabular}{|c|c|c|c|c|c|c|}
\hline & (a) All & PA case-studies include & & (b) Sensitivity analy & nabitat confounded stud & excluded \\
\hline & Target - protected & Target - non-protected & Non-target & Target - protected & Target - non-protected & Non-target \\
\hline & $N=7$ & $N=7$ & $\mathrm{~N}=4$ & $N=6$ & $N=4$ & $\mathbf{N}=\mathbf{2}$ \\
\hline rho $=0$ & $0.33[0.05 \rightarrow 0.61]$ & $0.27[0.03 \rightarrow 0.51]$ & - & $0.35[0.06 \rightarrow 0.63]$ & - & - \\
\hline rho $=0.2$ & $0.30[0.01 \rightarrow 0.58]$ & $0.28[0.03 \rightarrow 0.52]$ & - & $0.31[0.01 \rightarrow 0.60]$ & - & - \\
\hline rho $=0.5$ & $0.26[-0.02 \rightarrow 0.55]$ & $0.28[0.04 \rightarrow 0.52]$ & - & $0.26[-0.03 \rightarrow 0.56]$ & - & - \\
\hline rho $=0.8$ & $0.24[-0.06 \rightarrow 0.53]$ & $0.28[0.04 \rightarrow 0.53]$ & - & $0.24[-0.06 \rightarrow 0.53]$ & - & - \\
\hline rho $=1$ & $0.23[-0.07 \rightarrow 0.52]$ & $0.29[0.04 \rightarrow 0.53]$ & - & $0.22[-0.06 \rightarrow 0.52]$ & - & - \\
\hline
\end{tabular}

Results where different correlation coefficients (rho $=0,0.2,0.5,0.8,1$ ) among individual species responses were used to compute the within-study sampling variance are given on separate rows. The $\overline{L n R R}$ and $95 \% \mathrm{Cl}$ are given for analysis using (a) all MPA case-studies, and (b) excluding MPAs with habitat confounded effects. $\mathrm{N}$ represents the number of MPAs for each exploitation category. Sample size for non-target species was inadequate for the analysis. 
Table 12 The summary effect size $\overline{L n R R}$ and $[95 \% \mathrm{CI}]$ based on density data for each 'exploitation status' categories (target-protected [TP], target-not protected [TNP] and non-target [NT]), weighted by sampling variances

\begin{tabular}{lccccccc}
\hline & \multicolumn{3}{c}{ (a) All MPA case-studies included } & & \multicolumn{2}{c}{ (b) Sensitivity analysis; habitat confounded studies } \\
excluded
\end{tabular}

Results where different correlation coefficients (rho $=0,0.2,0.5,0.8,1)$ among individual species responses were used to compute the within-study sampling variance are given on separate rows. The $\overline{L n R R}$ and $95 \% \mathrm{Cl}$ are given for analysis using (a) all MPA case-studies, and (b) excluding MPAs with habitat confounded effects. $\mathrm{N}$ represents the number of MPAs for each exploitation category. $\overline{L n R R}>0$ means more fish inside the NTR; $\overline{L n R R}<0$ means fewer fish in the NTR. When the $\mathrm{Cl}$ overlaps 0 it implies a non-significant difference between NTR and PPA. $\mathrm{Q}_{M}$ values indicate the magnitude of the difference between exploitation categories.

Table 12). However, the magnitude of response to protection did not differ significantly among the three 'exploitation status' categories (sensitivity analysis: density at rho $0.5 ; \mathrm{Q}_{\mathrm{M}}=3.01, \mathrm{df}=3, \mathrm{p}=0.22$, Table 12 ).

MPA age, the size of the NTR relative to the PPA (size ratio) and the distance between the NTR and PPA did not explain the variation in the response of target species to protection, both for density (Table 13) and biomass (Table 14). The effect size for target species' biomass was positively related to the number of species pooled in the construction of the average effect size for each MPA (sensitivity analysis in Table 14).

Fish length The small number of studies precluded formal examination of the effect of full protection relative to partial protection on fish body size (i.e. mean length). In three out of five MPAs, target species length did not appear to be different between the NTR and the PPA (Figure 15). Similarly, in two out of three MPAs there was no difference in the body size (i.e. length) of nontarget species inside and outside the no-take reserve (the 95\% CI overlaps 0) (Figure 15).

Invertebrates: density, biomass, length Replication was sufficient only to assess the effect of protection on lobsters (Class: Decapoda) for target species and on sea urchins (class: Echinoidea) for non-target species. Lobster density was on average 1.76 times higher inside the NTR than in the PPA, and this increase was significant

Table 13 Summary of the simple regression models for each of the three moderator variables on target species density

\begin{tabular}{lccc}
\hline Moderator variable & $\mathbf{N}^{\mathbf{0}}$ MPAs & Slope $[\mathbf{9 5 \%} \mathbf{C l}]$ & $\mathbf{Q}_{\mathbf{M}}, \mathbf{p}$-val \\
\hline MPA age (year) & 18 & $0.03[-0.02 \rightarrow 0.09]$ & $\mathrm{Q}_{\mathbf{M}}=1.29, p=0.26$ \\
Size ratio (NTR:PPA) & 13 & $-0.11[-0.9 \rightarrow 0.69]$ & $\mathrm{Q}_{\mathbf{M}}=0.07, p=0.79$ \\
\# species combined & 18 & $-0.04[-0.14 \rightarrow 0.07]$ & $\mathrm{Q}_{\mathbf{M}}=0.51, p=0.47$ \\
\hline Sensitivity analysis; habitat confounded studies excluded & & \\
\hline Size ratio (NTR:PPA) & 11 & $-2.33[-5.12 \rightarrow 0.45]$ & $Q_{M}=2.70, p=0.1$ \\
\hline
\end{tabular}

Effect sizes are weighted by the variance of the mean of several correlated variables calculated for correlation coefficients of rho $=0.5$. Data under sensitivity analysis is given only for the moderator variable which showed considerable different result from when all studies were included. 
Table 14 Summary of the simple regression models for each of the four moderator variables on target species biomass

\begin{tabular}{lccc}
\hline Moderator variable & $\mathbf{N}^{\mathbf{0}}$ MPAs & Slope $[\mathbf{9 5 \%} \mathbf{C l}]$ & $\mathbf{Q}_{\mathbf{M}}, \mathbf{p}$-val \\
\hline MPA age (year) & 14 & $0.03[-0.005 \rightarrow 0.07]$ & $Q_{M}=2.89, p=0.09$ \\
Size ratio (NTR:PPA) & 11 & $-0.35[-0.92 \rightarrow 0.22]$ & $Q_{M}=1.45, p=0.23$ \\
Log(distance NTR to PPA) & 14 & $-0.09[-0.19 \rightarrow 0.02]$ & $Q_{M}=2.82, p=0.09$ \\
\# species combined & 14 & $0.002[-0.10 \rightarrow 0.11]$ & $Q_{M}=0.001, p=0.98$
\end{tabular}

Sensitivity analysis; habitat confounded studies excluded

$\begin{array}{llll}\text { \# species combined } & 10 & 0.10[0.02 \rightarrow 0.19] & Q_{M}=5.75, p=0.02\end{array}$

Effect sizes are weighted by the variance of the mean of several correlated variables calculated for correlation coefficients of rho $=0.5$. Data under sensitivity analysis is given only for the moderator variable which showed considerable different result from when all studies were included.

(Figure 16). The response of sea-urchins to protection was more variable and the overall mean effect size was only marginally significant $(\operatorname{Ln} R R=0.33, \quad C I=-0.02 \rightarrow 0.64)$ (Figure 16).

There was not enough data to investigate the response of invertebrate species to protection in terms of biomass and length, or to explore the influence of 'effect modifiers' on the response to protection.

\section{Discussion}

\section{Biological effects of MPAs}

Fish

Our synthesis suggests that while PPAs resulted in higher density and biomass than open (unprotected) areas, greatest benefits were apparent in NTR areas when NTRs and PPAs were compared. Improvements were largely driven by change in targeted fish species,

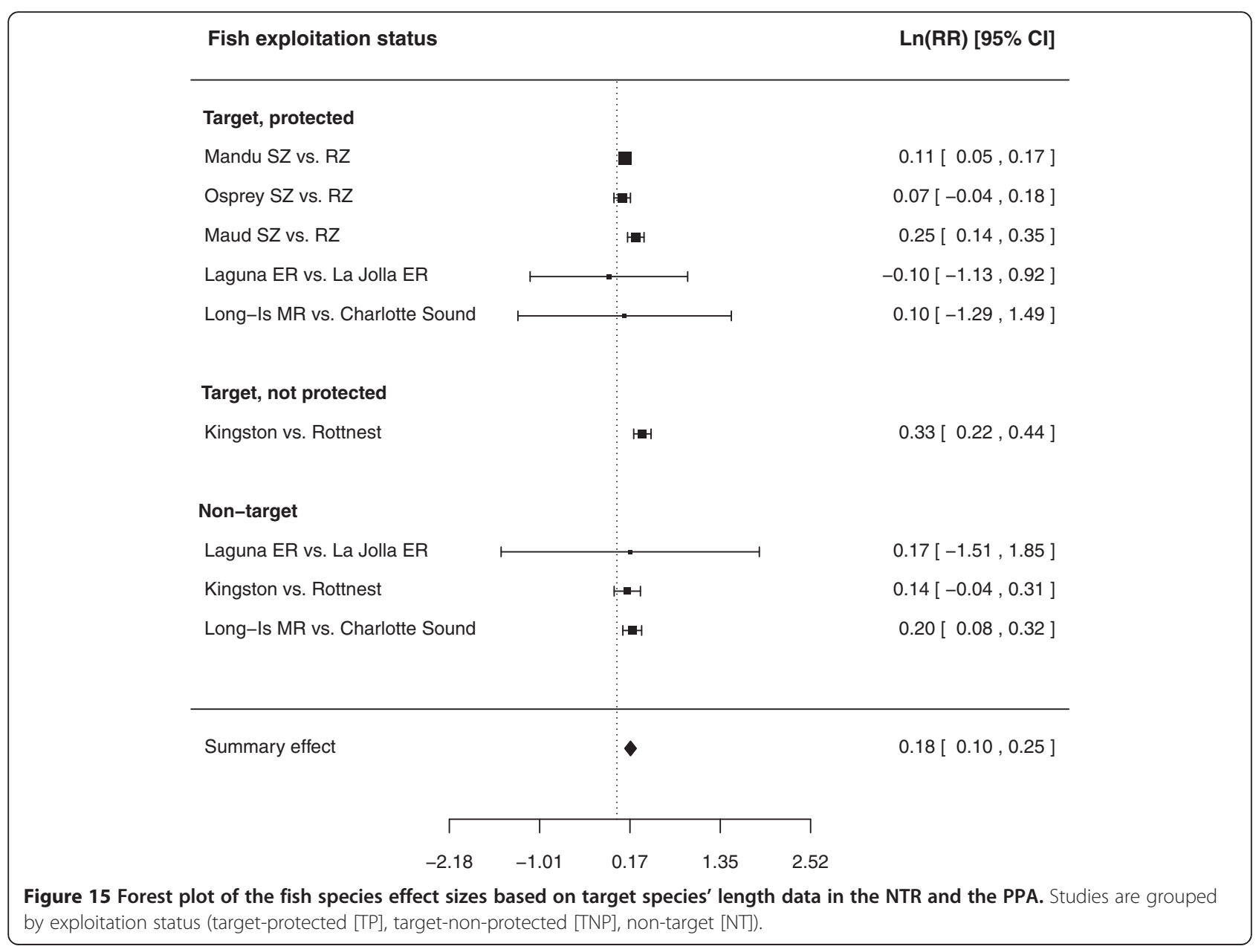




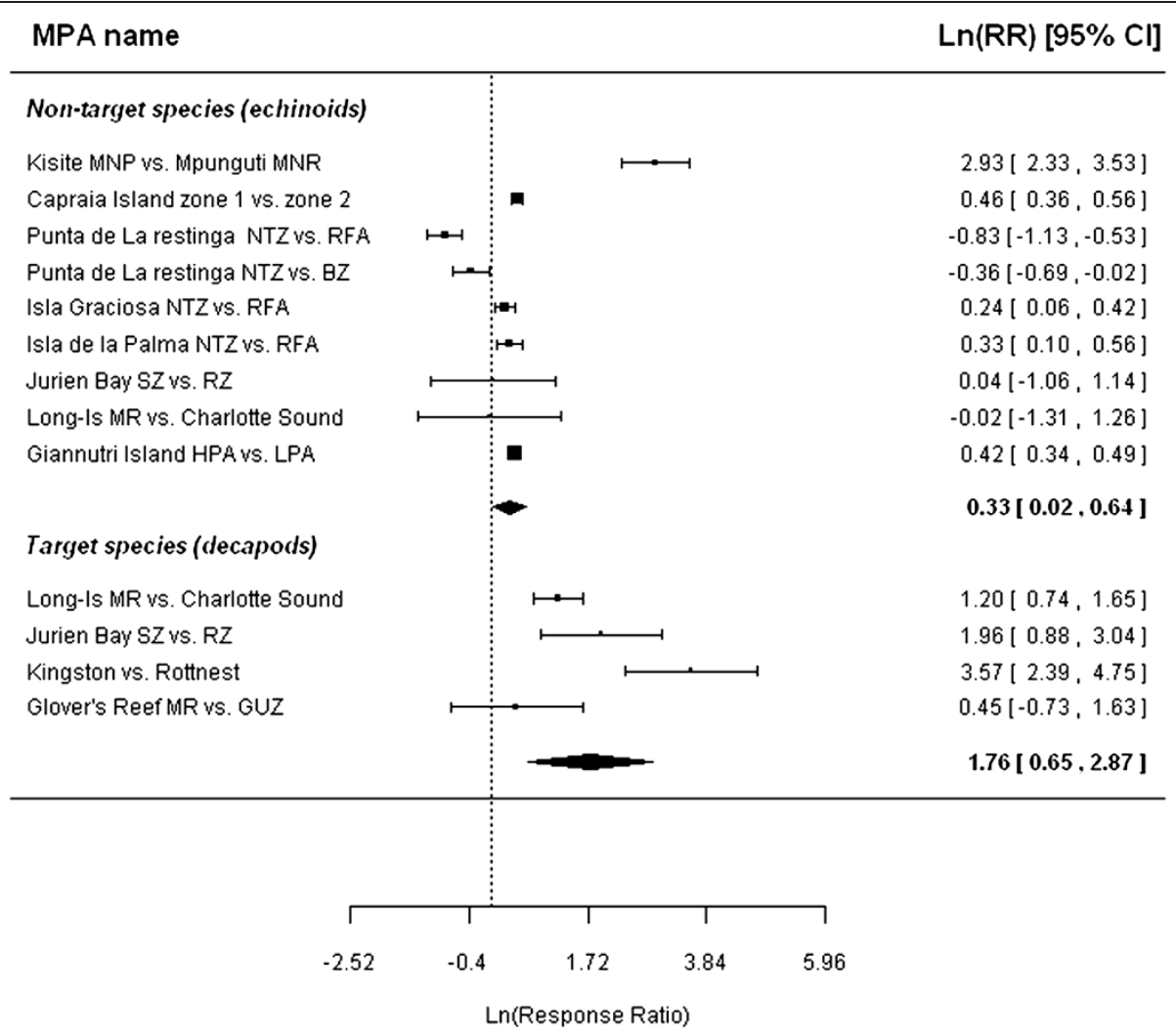

Figure 16 Forest plot of the response ratio (no-take:partial) of target and non-target invertebrate density categorized by taxonomic class. The vertical dotted line at $\overline{L n R R}=0$ represents equal invertebrate density inside and outside of the NTR. The squares are the effect size for each PPA, the error bars are the $95 \%$ confidence interval, whose values are given on the right hand side of the figure. The overall weighted mean effect is given by the 'Summary effect'.

and although positive benefits were also apparent in non-target species, the results were more variable, perhaps because of fewer studies focusing on this group.

MPAs may meet their objectives in a number of ways without necessarily excluding all extractive activities; habitat protection can be achieved by exclusion of benthic gears (e.g. [29,75,76]), avoidance of conflict can be achieved by spatial segregation of uses (e.g. [26,77]), sustainable exploitation or recovery of over-exploited fish stocks can occur within gear-specific exclusion areas (e.g. $[7,78])$. We have thus synthesized data for studies that have examined the effect of partially protected MPAs relative to open access areas to further increase our understanding of the potential value of those MPAs which strike a balance between allowing user access and achieving management and conservation measures. We found significantly higher density and biomass of fish inside the PPA relative to open access areas (Figures 5, 6). This finding contrasts with that by Lester and Halpern [40] in that they did not find significant ecological effects (in terms of density, biomass) of PPAs relative to Open areas, perhaps because they aggregated data across all taxa (fish, invertebrates, algae) and thus were not able to control for specific taxon traits or the exploitation status of the species included. Almost certainly, the frequency and intensity of exploitation experienced by a species in a fishery will greatly influence the magnitude of response to protection from fishing. For example, reductions in the spawning stock biomass resulting from high levels of fishing mortality, reduces the ability of fish populations to recover after a population decline [79]. Hence, the reduction or elimination of fishing mortality following the effective implementation of a MPA is expected to increase population density and biomass as stocks recover from exploitation. Indeed, we found that the positive response to protection in PPAs relative to Open areas was mainly driven by target species of commercial importance (Tables 4, 5). Furthermore, Lester and Halpern [40] acknowledge that failure to document significant effects of partially protected MPAs may have resulted from the fact that most of the studies they reviewed reported results for species targeted in both open access and partially protected areas. We have accounted for this potential effect modifier by keeping target species that are protected by the PPA (TP) separate from those not entirely protected in the PPA (TNP) and found significantly higher 
fish biomass inside the PPA relative to the Open area only for TP species (Table 5). Our analysis comparing PPAs to Open areas therefore suggests that well-managed PPAs with some restrictions on use are a valuable tool to counteract the decline of target populations, given that these are effectively protected under the protection regime in place.

Albeit, the higher benefits of PPAs over Open areas, we found greater benefits of protection in NTRs compared to PPAs. The response to protection (no-take:partial) was higher for fish biomass $(\overline{R R}=1.92)$ than for fish density $(\overline{R R}=1.11)$. One possible explanation for this discrepancy in protection effect between density and biomass is that the density of individuals is susceptible to stochastic recruitment events, such that the movement of juvenile fish across the no-take reserve boundary into the adjacent partially protected area may have resulted in the smaller magnitude of protection effect observed for fish density. The high positive response for fish biomass provides evidence towards the protection benefit of fully protected areas from size-selective fishing or accidental catch. In their review of the benefits of NTRs over PPAs, Lester and Halpern [40] also reported stronger effects of protection for NTRs than for PPAs. However, whereas we found significantly higher response for biomass than for density, Lester and Halpern [40] reported significantly higher response ratios (no-take:partial) for density $(\overline{R R}=1.79)$ but not for biomass $(\overline{R R}=1.22)$. As alluded above, one important difference between the two syntheses is that whereas our study focussed on fish species only, Lester and Halpern [40] aggregated data across broad taxonomic groups (fish, invertebrates, algae) with different life history (e.g. growth rate) and ecological characteristics (e.g. larval dispersal potential, adult mobility). For example, the sessile nature and the relative low mobility of some species (e.g. urchins, gastropods, corals, sponges) included in Lester and Halpern [40], might have resulted in the larger differences in density that they observed between notake reserves and partially protected areas.

\section{Invertebrates}

The studies on target invertebrate species focused mainly on scallops and lobsters, for which strong positive effect sizes were reported for both density and biomass in the partially protected area relative to open access area, and also in the no-take reserve relative to the partially-protected area. This is in agreement with findings in other studies that reported positive responses for lobster populations following marine reserve designation, possibly owing to the species' short home range and migration to deeper waters where fishing pressure is generally lower (e.g.
[80-83]). The cessation of scallop dredging not only reduces fishing mortality of adult scallops [27], but also eliminates the deleterious effects on benthic communities [84]. Closed areas with significantly greater biomass of attached species such as hydroids have been suggested to be important settlement substrata for pectinid larvae $[85,86]$, so that protection during this critical phase may assist in the recovery of scallop populations in the closed area.

The studies on non-target invertebrate species focused mainly on echinoids. The response of nontarget echinoid species to protection was considerably variable. Overall, we found lower density and biomass of non-target invertebrate species inside partially protected areas compared to open areas, but did not find significant difference in density between fullyand partially-protected areas. This variability may be explained through a number of factors. Some studies linked the lower abundance of sea urchins inside MPAs to the increase in predation pressure following the recovery of predatory fish populations after protection $[18,87,88]$. Alternatively, factors such as higher spatial heterogeneity and availability of shelter (e.g. more crevices) inside the MPA have been linked to higher abundance of sea urchins in MPAs, as these may reduce the exposure of urchins to fish predators $[89,90]$.

\section{Reasons for variation in effectiveness}

There was a large degree of variability in the magnitude of response to protection and MPA success was highly variable. The factors determining such variation were generally unclear although the size of the PPA explained some of this variability. Examination of the protection regime within the partially protected area provided novel insights into the efficacy of partial MPAs for conservation and management.

We found that the 'protection regime', which defined the amount of protection afforded to species by the partially protected area, was a key determinant of the magnitude of MPA efficacy. Of the three categories of protection regime (IdC, DC, DR), our analysis revealed that the response of target fish species to partial protection was the largest for partially protected areas that excluded commercial fishing with mid-water gear but permitted fishing on a recreational basis (DR). Such protection regimes typically exist in tropical and subtropical regions (e.g. $[19,25,64,66,91])$. Interestingly, such protection resulted in greater positive response than those MPAs (typically found in temperate regions) which excluded bottom-towed gear but allowed fishing with mid-water gear (e.g. nets and long-lines) or static gear (e.g. pots, traps). This is perhaps counter-intuitive given the well-recognized negative impact of bottom-towed 
fishing gear on biota and habitat [92-94]. However, MPAs that excluded bottom towed gear were typically established to protect large mobile demersal fish such as cod, haddock, hake and saithe (e.g. [60,67,95]), which are likely to experience less benefits from protection (e.g. compared to reef-associated species) due to their high mobility and dispersal distances. Additionally, benthopelagic species that rely on benthic invertebrates for their food might take longer to respond to protection as habitat recovery following disturbance by bottomtowed gear will have to occur before these species can begin to recover.

Interestingly, we found that increasing the size of the PPA, in particular above $1000 \mathrm{~km}^{2}$, reduced the effectiveness of partial protection relative to no protection for fish assemblages as well as for fish target species. This was somewhat surprising given that previous theoretical and empirical studies have shown that larger no-take reserves are more effective at increasing biodiversity and density of commercial species $[35,96,97]$. It is not unrealistic to assume that non-compliance and infringement of regulations are more likely in large than in small MPAs [98]. The size of the partially protected areas in the dataset comparing PPAs to Open areas ranged between 1.5 $\mathrm{km}^{2}$ and $11980 \mathrm{~km}^{2}$ and although a single instance of illegal fishing in a small PPA can have a more damaging effect than in a large PPA, it is more likely that the occurrence of illegal fishing is higher in large PPAs. This may explain the lower effectiveness of protection that we observed for partially protected areas over $1000 \mathrm{~km}^{2}$ in size. Another possible explanation for results not conforming to expectation is the inadequacy of the sampling effort and replication. Among the studies included in our analysis, the majority (24 out of 27) surveyed an area equivalent to less than $1 \%$ of the total area of the PPA, raising issues about the representativeness of the observations for the entire MPA. The proportion of area surveyed for MPAs larger than $20 \mathrm{~km}^{2}$ was only $0.1 \%$ of the MPA area, suggesting that the sampling in large MPAs may have inadequate power to detect subtle changes in density or biomass between the protected and unprotected areas.

\section{Key challenges met in this review}

Confounded baselines have been identified as barriers to the interpretation of MPA studies previously $[30,31,73,99]$ and they remain a hindrance in this analysis. A first source of confounding emerges from the fact that habitat structure may not be comparable between the protected and unprotected areas. Some authors have argued that the apparent effect of protection is not due to protection per se, but rather due to higher-quality habitat before the onset of protection (e.g. $[5,55])$ or due to site-specific features in reserves that differ from those in control areas [5,13,54,100]. A strong-point of this meta-analysis is that we tried to minimize habitat bias on protection effect by running a sensitivity analysis alongside the main analysis, whereby studies with reported habitat differences between the protected and control area were excluded from the sensitivity analysis (e.g. [64,101]). The analyses have shown several instances when the outcome of the sensitivity and main analyses were different. For example, the magnitude of the effect size comparing PPAs to Open areas for fish density was smaller when the habitatconfounded studies were removed from the analysis. The positive effect of protection (partial:open) on nontarget fish species changed from significant to nonsignificant when the habitat-confounded studies were excluded from the analysis. Other times, the two analyses did not differ. For example, the response for fish assemblage density in NTRs relative to PPAs was not significant, whether the 'habitat-confounded' studies were removed from the full dataset or not. These observations highlight the importance of examining the influence of habitat effects on the response of biota to protection in future assessments of MPA efficacy. Furthermore, the implications of ignoring confounding effects due to habitat differences between protected and control areas means that potentially unreliable and biased recommendations are made to policy-makers and conservation managers about the effects of protection.

The identification of 'habitat-confounded' studies has been a challenge in itself. Although most studies in this review stated whether sampling occurred on seagrass meadows (e.g. [102-104]) or rocky bottoms (e.g. $[45,56,66,105])$ or coral reefs (e.g. $[65,91,106-110]$ ), there was a general lack of data quantifying the relationship between biota and habitat structure inside and outside the MPA (but see [45,91,101,108-112]). We could only identify 'habitat-confounded' studies with confidence when the authors explicitly reported significant differences in habitat among the sites studied inside and outside the MPA. Given that most studies did not examine the variation in habitat structure between protected and control areas, it is possible that some potentially habitat-confounded studies were not excluded from the sensitivity analysis, albeit our best efforts to eliminate this bias. We stress therefore, the importance for future studies to measure habitat covariates alongside biological data if assessment of change in a community is to be related to protection or to an intrinsic structural feature of the protected area.

A further challenge was controlling for the range and intensity of activities permitted within the PPAs as information on fishing intensity and effort 
characteristic of the fishery in the PPA was essentially negligible. In the absence of such detailed information, we used information on whether the permitted activities inside the PPA occurred on a commercial or recreational basis to define PPA protection regime categories. We based this categorization on the assumption that fishing pressure and efficiency are lower for recreational fishing than for commercial fishing practices. Although this assumption holds true for some recreational fisheries, there is a growing body of evidence indicating that recreational fishing can constitute a significant portion of the regional catch for some species $[113,114]$. We recommend that measures of fishing pressure such as the number of traps per area, the number of vessels/nets per area, the number of spear fishers allowed per annum and the time spent at sea are reported in future MPA studies.

\section{Key limitations}

A number of key limitations encountered in this review are worth highlighting. First was the lack of data on the historic levels of exploitation inside the MPA prior to its designation, which is one factor highly likely to influence the magnitude of protection effect. For example, Edgar et al. [112] found low level of change for fish between the MPA and fished areas because pre-existent fishing pressure across the region was low and historically depressed stocks only slightly. Conversely, McLean et al. [115] found very little change between protected and unprotected populations of Lethrinus harak even after 15 years of protection because previously high levels of exploitation combined with low recruitment years for this species led to large reductions in the abundance of this species across the region. Second was the insufficient information on the range and relative intensity of exploitation activities in reference fished areas. The majority of studies only provided a very vague description of activities in the unprotected control area (e.g. "fully open to fishing" [25]; "all kinds of commercial and recreational fishing" [116], but see Forcada et al. [117]). Information about the relative intensity of exploitation was even scarcer (but see $[45,67,118-121])$. Two examples that show the potentially important implications of exploitation intensity in the control area for a within-context interpretation of the magnitude of protection effect include a study by Iacchei et al. [119] on lobster density and another by Tupper and Rudd [91] on target fish density. Iacchei et al. [119] recorded a 3\% increase in lobster (Panulirus interruptus) density in the MPA relative to a recreationally fished control area where lobsters were caught by hand or hoop nets and catches were limited to a daily bag limit of 7 lobsters per person. In contrast, when they compared the MPA to a commercially fished area where fishing occurred by 3-5 fishers using 750-1000 traps, lobster density was 57\% higher inside the MPA than outside. Similarly, Tupper and Rudd [91] found that fish density was 9 times higher in the MPA when compared to a moderately fished area $(\operatorname{Ln} R R=1.03)$ than when compared to a lightly fished area $(\operatorname{Ln} R R=0.11)$. These examples serve to show the importance of including exploitation intensity inside and outside the MPA for a more within-context interpretation of the efficacy of MPAs, which remain somewhat overlooked in most studies including those reviewed in this study.

A valid constraint that needs to be acknowledged in our analyses is that response variables (density, biomass, length, species diversity) comparisons were based on single snapshot datasets after MPA establishment. Only a handful of studies included in our analysis were based on strong experimental designs such as BACI and beyond-BACI studies [53,122] (see Additional file 5). Ecosystem processes are spatially and temporally variable at multiple scales and these variations can obscure the detection of the effects of protection [52].

Pooling of individual species responses for MPAlevel analyses may introduce methodological bias. For example, studies that have measured large numbers of species may exhibit stronger positive responses due to the higher probability of including species that benefit from protection. The number of species pooled together to create average effect sizes for each 'exploitation status' category was found to be significantly related to the magnitude of response of target species biomass to protection in fully- vs. partially-protected areas. Although this covariate did not influence target species density or the effect size comparing partiallyvs. open areas, we cannot rule out the potential methodological bias introduced by pooling individual species responses.

Small sample sizes and lack of power are clearly problematic in some instances, for example invertebrate species and biological measures such as species length. The limited number of studies made it hard to draw firm conclusions about the impact of protection on this group of organisms and biological measure.

\section{Concluding remarks}

\section{Implications for management / policy / conservation}

This review addressed an important question for managers and policy-makers of whether partially protected areas are an effective management option for conservation and fisheries compared to fully 
protected and open areas. The available evidence suggests that no-take reserves provide some benefit over less protected areas, nevertheless the significant ecological effects of partially protected areas relative to open access areas suggest that partially protected areas are a valuable spatial management tool particularly in areas where exclusion of all extractive activities is not a socio-economically and politically viable option. Change in the distribution of fishing effort could result in economically negligible net benefits [123] or may be detrimental to habitats previously undisturbed by anthropogenic activities [124]. Hence, while acknowledging that MPAs are not a panacea for conservation and fisheries management, under the right conditions (that may include additional reduction of fishing effort in fishing grounds surrounding MPAs, or a network of MPAs that allow a mix of protection levels, or involvement of multiple stakeholder groups during the designation process), MPAs offering partial protection are valuable tools for the preservation and enhancement of fish and invertebrate populations.

\section{Implications for research and further work}

Lack of data is a hindrance in the development of an evidence-base regarding the effectiveness of marine protected areas. Small sample sizes result in high uncertainty about the impacts on specific taxa, in particular, invertebrates, and species groups such as non-target fish species. Insufficient data are available regarding species richness and length (i.e. body size) of individual species and the effect of protection in soft sediment systems. It is also very difficult to distinguish habitat effects from reserve effects without integrated experimental monitoring programs that present data regarding the baseline condition. Hence, we urge future studies to measure habitat covariates alongside biological data. Given the clear evidence of the influence of exploitation intensity on MPA performance, we stress that measures of the fishing pressure outside the MPA, the historic levels of exploitation within the MPA prior to designation and the range of restricted and permitted activities within partially protected MPAs should be routinely reported as these factors allow for a robust withincontext interpretation of the protection effect. Data regarding the degree of enforcement and compliance inside an MPA are required alongside biological metrics for monitoring to be effective. Whilst acknowledging the time constraints and increased financial costs associated with BACI empirical studies, we advocate that the controversy as to whether any differences are a consequence of protection or are merely coincidental can only be satisfactorily addressed by further monitoring incorporating assessment of change from baseline conditions.

\section{Appendix}

Table 15 shows glossary of terms.

\section{Table 15 Glossary of terms}

\begin{tabular}{|c|c|c|}
\hline \multicolumn{3}{|c|}{ Glossary } \\
\hline Abb. & Term & Definition \\
\hline MPA & Marine Protected Area & $\begin{array}{l}\text { Discrete geographic areas of the sea that are protected by spatially explicit restrictions designated } \\
\text { under international, national, tribal or local laws to enhance long-term conservation of natural } \\
\text { resources therein. }\end{array}$ \\
\hline NTR & No-take reserve & MPAs where all anthropogenic activities are excluded, apart from scientific research. \\
\hline PPA & Partially protected area & MPAs whereby regulations restrict some extractive uses but permit others. \\
\hline Open & Open access area & Areas outside the MPA that are open to fishing. \\
\hline $\mathrm{TP}$ & Target-protected species & Target species that were protected in both the NTR and the PPA \\
\hline TNP & Target non-protected species & Target species that were protected in the NTR but still allowed to be fished inside the PPA \\
\hline NT & Non-target species & $\begin{array}{l}\text { Species for which fishing gear is not specifically set, although the possibility that these species are } \\
\text { accidentally caught as by-catch cannot be ruled out }\end{array}$ \\
\hline $\mathrm{IdC}$ & Indiscriminate, commercial PPA & $\begin{array}{l}\text { PPAs that prohibit fishing activities which are damaging to bottom habitats and non-target species (e. } \\
\text { g. scallop dredging, bottom trawling) but allow other forms of commercial fishing with mid-water } \\
\text { towed gear or static bottom gear }\end{array}$ \\
\hline DC & Discriminate, commercial PPA & $\begin{array}{l}\text { PPAs that prohibit activities which affect particular target species but not the surrounding environment } \\
\text { (e.g. seine nets, long lines, spearfishing) but allow subsistence fishing on a commercial basis }\end{array}$ \\
\hline $\mathrm{DR}$ & Discriminate, recreational PPA & $\begin{array}{l}\text { PPAs that prohibit activities which affect particular target species but not the surrounding environment } \\
\text { (e.g. seine nets, long lines, spearfishing) but allow fishing on a recreational basis }\end{array}$ \\
\hline $\mathrm{BACl}$ & Before-After-Control-Impact study & \\
\hline $\mathrm{Cl}$ & Control-Impact study & \\
\hline
\end{tabular}




\section{Additional files}

Additional file 1: Systematic review search terms.
Additional file 2: Data extraction form.
Additional file 3: Protection regime categorization scheme.
Additional file 4: List of excluded studies \& reasons for exclusion.
Additional file 5: Description of MPA \& methodology characteristics
for the studies included in the review.

\section{Competing interests}

None identified. The research work for this publication was partially funded by the Malta Government Scholarship Scheme grant number MGSS PHD 2008-02, the IMAREST Stanley-Gray Fellowship 2008/2009 and the David Edwards Memorial Award, Bangor University.

\section{Authors' contributions}

MS designed the systematic review, carried out the literature search, performed the statistical analyses, and wrote the protocol and manuscript. ASP directed the conduct of the systematic review. SRJ and SJH checked for consistency in the study inclusion (second and third reviewers). ASP, SRJ, $\mathrm{SJH}, \mathrm{MJK}$ supervised the work, advised on analysis and provided thorough editing of the manuscript. All authors commented and approved the final manuscript.

\section{Acknowledgements}

We thank Rebecca Mant and Elena Kulinskaya for discussions about the dataset and statistical assistance. Thanks to all authors of the included papers in this review, who contributed additional data and details about their studies on MPAs whenever necessary.

\section{Author details}

${ }^{1}$ School of Ocean Sciences, Bangor University, Menai Bridge, Anglesey LL59 5AB, UK. Ocean and Earth Science, National Oceanography Centre Southampton, University of Southampton, Southampton SO16 4ZH, UK. ${ }^{3}$ Centre for Evidence-Based Conservation, School of the Environment, Natural Resources and Geography, Bangor University, Bangor LL57 2UW, UK.

Received: 24 July 2012 Accepted: 13 February 2013

Published: 28 February 2013

\section{References}

1. Boersma PD, Parrish JK: Limiting abuse: marine protected areas, a limiting solution. Ecol Econ 1999, 31(2):287-304.

2. Millennium Ecosystem Assessment: Ecosystems and human well-being: Biodiversity synthesis. Washington: World Resources Institute; 2005.

3. NRC: Marine Protected Areas. Tools for sustaining ocean ecosystems. National Research Council (NRC), Committee on the Evaluation, Design, and Monitoring of Marine Reserves and Protected Areas in the United States. Washington: National Academy Press; 2001:272.

4. Roberts CM, Bohnsack JA, Gell F, Hawkins JP, Goodridge R: Effects of marine reserves on adjacent fisheries. Science 2001, 294:1920-1923.

5. Willis TJ, Millar RB, Babcock RC: Protection of exploited fish in temperate regions: high density and biomass of snapper Pagrus auratus (Sparidae) in northern New Zealand marine reserves. J App/ Ecol 2003, 40:214-227.

6. Lindeman KC, Pugliese C, Waugh GT, Ault JS: Developmental patterns within a multispecies reef fishery: Management applications for essential fish habitats and protected areas. Bull Mar Sci 2000, 66(3):929-956.

7. Murawski SA, Brown R, Lai HL, Rago PJ, Hendrickson L: Large-scale closed areas as a fishery-management tool in temperate marine systems: The Georges Bank experience. Bull Mar Sci 2000, 66(3):775-798.

8. Gell FR, Roberts CM: Benefits beyond boundaries: the fishery effects of marine reserves and fishery closures. Trends Ecol Evol 2003, 18:448-455.

9. Browman HI, Stergiou Kl: Marine protected areas as a central element of ecosystem-based management: defining their location, size and number. Mar Ecol Prog Ser 2004, 274:271-272.

10. Sissenwine M, Murawski S: Moving beyond 'intelligent tinkering': Advancing an ecosystem approach to fisheries. Mar Ecol Prog Ser 2004, 274:291-295.
11. Lauck T, Clark CW, Mangel M, Munro GR: Implementing the precautionary principle in fisheries management through marine reserves. Ecol Appl 1998, 8:72-78.

12. Garcia-Rubies A, Zabala M: Effects of total fishing prohibition on the rocky fish assemblages of Medes Islands marine reserve (NW Mediterranean). Sci Mar 1990, 54(4):317-328.

13. Garcia-Charton JA, Perez-Ruzafa A, Sanchez-Jerez P, Bayle-Sempere JT, Renones O, Moreno D: Multi-scale spatial heterogeneity, habitat structure, and the effect of marine reserves on Western Mediterranean rocky reef fish assemblages. Mar Biol 2004, 144:161-182.

14. Guidetti P, Bussotti S, Boero F: Evaluating the effects of protection on fish predators and sea urchins in shallow artificial rocky habitats: A case study in the northern Adriatic Sea. Mar Environ Res 2005, 59:333-348.

15. Planes S, Galzin R, Garcia Rubies A, Goni R, Harmelin JG, Le Direach L, Lenfant $P$, Quetglas A: Effects of marine protected areas on recruitment processes with special reference to Mediterranean littoral ecosystems. Environ Conserv 2000, 27(2):126-143.

16. Goni R, Quetglas A, Renones O: Size at maturity, fecundity and reproductive potential of a protected population of the spiny lobster Palinurus elephas (Fabricius, 1787) from the western Mediterranean. Mar Biol 2003, 143:583-592.

17. Castilla JC: Coastal marine communities: trends and perspectives from human exclusion experiments. Trends Ecol Evol 1999, 14:280-283.

18. Shears NT, Babcock RC: Marine reserves demonstrate top-down control of community structure on temperate reefs. Oecologia 2002, 132:131-142.

19. Chapman MR, Kramer DL: Gradients in coral reef fish density and size across the Barbados marine Reserve boundary: effects of reserve protection and habitat characteristics. Mar Ecol Prog Ser 1999, 181:81-96.

20. Goni R, Quetglas A, Renones O: Spillover of spiny lobsters Palinurus elephas from a marine reserve to an adjoining fishery. Mar Ecol Prog Ser 2006, 308:207-219.

21. Halpern BS, Lester SE, Kellner JB: Spillover from marine reserves and the replenishment of fished stocks. Environ Conserv 2010, 36(4):268-276.

22. Richardson EA, Kaiser MJ, Edwards-Jones G, Possingham HP: Sensitivity of marine-reserve design to the spatial resolution of socioeconomic data. Conserv Biol 2006, 20(4):1191-1202.

23. Fiske SJ: Sociocultural aspects of establishing marine protected areas. Ocean Coast Manage 1992, 18:25-46.

24. Steele JH, Beet AR: Marine protected areas in 'nonlinear' ecosystems. Proceedings of the Royal Society of London B 2003, 270:S230-S233.

25. Denny CM, Babcock RC: Do partial reserves protect reef fish assemblages? Biol Conserv 2004, 116:119-129.

26. Pipitone C, Badalamenti F, D'Anna G, Patti B: Fish biomass increase after a four-year trawl ban in the Gulf of Castellammare (NW Sicily, Mediterranean Sea). Fish Res 2000, 48:23-30.

27. Beukers-Stewart BD, Vause BJ, Mosley MWJ, Rossetti HL, Brand AR: Benefits of closed area protection for a population of scallops. Mar Ecol Prog Ser 2005, 298:189-204.

28. Piet GJ, Rijnsdrop AD: Changes in the demersal fish assemblage in the south-eastern North Sea following the establishment of a protected area ("plaice box"). ICES J Mar Sci 1998, 55:420-429.

29. Roberts CM, Polunin NVC: Are marine reserves effective in management of reef fisheries? Rev Fish Biol Fisher 1991, 1:65-91.

30. Mosquera I, Cote IM, Jennings S, Reynolds S: Conservation benefits of marine reserves for fish populations. Anim Conserv 2000, 3:321-332.

31. Cote IM, Mosqueira I, Reynolds JD: Effects of marine reserve characteristics on the protection of fish populations: a meta-analysis. J Fish Biol 2001, 59(Suppl A):178-189.

32. Fraschetti S, Terlizzi A, Micheli F, Benedetti-Cecchi L, Boero F: Marine protected areas in the Mediterranean Sea: Objectives, effectiveness and monitoring. Mar Ecol 2002, 23(S1):190-200.

33. Halpern BS: The impact of marine reserves: Do reserves work and does reserve size matter? Ecol Appl 2003, 13(1):117-137.

34. Ojeda-Martinez C, Bayle-Sempere JT, Sanchez-Jerez P, Forcada A, Valle C: Detecting conservation benefits in spatially protected fish populations with meta-analysis of long term monitoring data. Mar Biol 2007, 151:1153-1161.

35. Claudet J, Osenberg CW, Benedetti-Cecchi L, et al: Marine reserves: size and age do matter. Ecol Lett 2008, 11:481-489. 
36. Garcia-Charton JA, Perez-Ruzafa A, Marcos C, et al: Effectiveness of European Atlanto-Mediterranean MPAs: do they accomplish the expected effects on populations, communities and ecosystems? J Nat Conserv 2008, 16:193-221.

37. Lester SE, Halpern BS, Grorud-Colvert K, Lubchenco J, Ruttenberg BI, Gaines SD, Airame S, Warner RR: Biological effects within no-take marine reserves: a global analysis. Mar Ecol Prog Ser 2009, 384:33-46.

38. Maliao RJ, White AT, Maypa AP, Turigan RG: Trajectories and magnitude of change in coral reef fish populations in Philippine marine reserves: a meta-analysis. Coral Reefs 2009, 28:809-822.

39. Vandeperre F, Higgins RM, Sanchez-Meca J, Maynou F, Goni R, Martin-Sosa $P$, et al: Effects of no-take area size and age of marine protected areas on fisheries yields: a meta-analytical approach. Fish Fish 2011, 12:412-426.

40. Lester SE, Halpern BS: Biological responses in marine no-take reserves versus partially protected areas. Mar Ecol Prog Ser 2008, 367:49-56.

41. Stewart GB, Cote IM, Kaiser MJ, Halpern BS, Lester SE, Bayliss HR, Mengersen K, Pullin AS: Are marine protected areas effective tools for sustainable fisheries management? I. Biodiversity impact of marine reserves in temperate zones. In Systematic Review No. 23. Collaboration for Environmental Evidence. 2008.

42. Gates S: Review of methodology of quantitative reviews using metaanalysis in ecology. J Ani Ecol 2002, 71:547-557.

43. Roberts PD, Stewart GB, Pullin AS: Are review articles a reliable source of evidence to support conservation and environmental management? A comparison with medicine. Biol Conserv 2006, 132:409-423.

44. Stewart GB, Coles CF, Pullin AS: Applying evidence-based practice in conservation management: Lessons from the first systematic review and dissemination projects. Biol Conserv 2005, 126(2):270-278.

45. Tetreault I, Ambrose RF: Temperate marine reserves enhance targeted but not untargeted fishes in multiple no-take MPAs. Ecol Appl 2007, 17(8):2251-2267.

46. Williamson DH, Russ GR, Ayling AM: No-take marine reserves increase abundance and biomass of reef fish on inshore fringing reefs of the Great Barrier Reef. Environ Conserv 2004, 31(2):149-159.

47. Watson DL: Anderson, MJ, Kendrick GA, Nardi K, Harvey ES: Effects of protection from fishing on the lengths of targeted and non-targeted fish species at the Houtman Abrolhos Islands, Western Australia. Mar Ecol Prog Ser 2009, 384:241-249.

48. Molloy PP, McLean IB, Cote IM: Effects of marine reserve age on fish populations: a global meta-analysis. J Appl Ecol 2009, 46:743-751.

49. Claudet J: Marine protected areas: a multidisciplinary approach. UK: Cambridge University Press; 2011

50. Friedlander AM, Brown EK, Jokei PL, Smith WR, Rodgers KS: Effects of habitat, wave exposure, and marine protected area status on coral reef fish assemblages in the Hawaiian archipelago. Coral Reefs 2003, 22(3):291-305.

51. Carletta J: Assessing agreement on classification tasks: The kappa analysis. Computational Linguistics 1996, 22(2):249-254.

52. García-Charton JA, Pérez-Ruzafa A: Ecological heterogeneity and the evaluation of the effects of marine reserves. Fish Res 1999, 42:1-20.

53. Guidetti P: The importance of experimental design in detecting the effects of protection measures on fish in Mediterranean MPAs. Aquat Conserv Mar Freshwat Ecosyst 2002, 12:619-634.

54. Claudet J, Garcia-Charton JA, Lenfant P: Combined effects of level of protection and environmental variables at different spatial resolutions on fish assemblages in a Marine Protected Area. Conserv Biol 2011, 25(1):105-114.

55. Edgar GJ, Bustamente RH, Farina JM, Calvopina M, Martinez C, Toral-Granda MV: Bias in evaluating the effects of marine protected areas: the importance of baseline data for the Galapagos Marine Reserve. Environ Conserv 2004, 31(3):212-218.

56. Tuya F, Garcia-Diez C, Espino F, Haroun RJ: Assessment of the effectiveness of two marine reserves in the Canary Islands (eastern Atlantic). Ciencias Marinas 2006, 32(3):505-522.

57. Borenstein M, Hedges LV, Higgins JPT, Rothstein HR: Introduction to MetaAnalysis. Chichester: John Wiley \& Sons Ltd; 2009.

58. Nardi K, Jones GP, Moran MJ, Cheng YW: Contrasting effects of marine protected areas on the abundance of two exploited reef fishes at the sub-tropical Houtman Abrolhos Islands, Western Australia. Environ Conserv 2004, 31(2):160-168.

59. Walsh WJ, Tissot BN, Hallacher LE: A report on the findings and recommendations of effectiveness of the West Hawaii Regional Fishery
Management Area. In Report to the Twenty-Third Hawai'i Legislature Regular Session of 2005. 2004:38.

60. Link J, Almeida F, Valentine P, Auster P, Reid R, Vitaliano J: The effects of area closures on Georges Bank. In Benthic Habitats and the Effects of Fishing (American Fisheries Society, Symposium 41, Bethesda, Maryland, 12-14 November, 2002). Edited by Barnes PW, Thomas JP. USA: American Fisheries Society; 2005:345-368.

61. Friedlander AM, Brown E, Monaco ME, Clark A: Fish habitat utilization patterns and evaluation of the efficacy of Marine Protected Areas in Hawaii: Integration of NOAA digital benthic habitat mapping and coral reef ecological studies. Silver Spring: NOAA Technical Memorandum NOS NCCOS 23; 2006:217.

62. Friedlander AM, Wedding LM, Brown E, Monaco ME: Monitoring Hawaii's Marine Protected Areas: Examining spatial and temporal trends using a seascape approach. Silver Spring: NOAA Technical Memorandum NOS NCCOS 117; 2010:130.

63. La Mesa G, Vacchi M: An analysis of the coastal fish assemblage of the Ustica Island Marine Reserve. PSZN I: Marine Ecology 1999, 20:147-165.

64. Miller R, Williams B, Duffy C: Reef fish of the Sugar Loaf Islands (Ngä Motu) Marine Protected Area, New Zealand. DOC Research \& Development Series 2005, 226:26.

65. Tupper $\mathrm{MH}$ : Spillover of commercially valuable reef fishes from marine protected areas in Guam, Micronesia. Fish Bull 2007, 105(4):527-537

66. Di Franco A, Bussotti S, Navone A, Panzalis P, Guidetti P: Evaluating effects of total and partial restrictions to fishing on Mediterranean rocky-reef fish assemblages. Mar Ecol Prog Ser 2009, 387:275-285.

67. Jaworski A, Solmundsson J, Ragnarsson SA: Fish assemblages inside and outside marine protected areas off northern Iceland: protection effects or environmental confounds? Fish Res 2010, 102:50-59.

68. Hedges LV, Gurevitch J, Curtis PS: The meta-analysis of response ratios in experimental ecology. Ecology 1999, 80(4):1150-1156.

69. Rosenberg MS, Adams DC, Gurevitch J: MetaWin: Statistical software for meta-analysis, version 2.0. New York: Sinauer Associates, Inc; 2000.

70. Raudenbush SW, Becker BJ, Kalaian H: Modeling multivariate effect sizes. Psychol Bull 1988, 103:111-120.

71. Hedges LV, Tipton E, Johnson MC: Robust variance estimation in metaregression with dependent effect size estimates. Research Synthesis Methods 2010, 1:39-65.

72. Thompson SG, Higgins JPT: How should meta-regression analyses be undertaken and interpreted? Stat Med 2002, 21:1559-1573.

73. Micheli F, Halpern BS, Botsford LW, Warner RR: Trajectories and correlates of community change in no-take marine reserves. Ecol Appl 2004 14(6):1709-1723

74. Viechtbauer $\mathrm{W}$ : Conducting meta-analyses in $\mathrm{R}$ with the metaphor package. J Stat Softw 2010, 36(3):1-48.

75. Fogarty MJ, Murawski SA: Large-scale disturbance and the structure of marine systems: Fishery impacts on Georges Bank. Ecol App/ 1998, 8(1):S6-S22.

76. Smith MD, Grabowski JH, Yund PO: The role of closed areas in rebuilding monkfish populations in the Gulf of Maine. ICES J Mar Sci 2008, 65(7):1326-1333.

77. Blyth RE, Kaiser MJ, Edwards-Jones G, Hart PJB: Voluntary management in an inshore fishery has conservation benefits. Environ Conserv 2002, 29(4):493-508.

78. Fisher JAD, Frank KT: Changes in finfish community structure associated with an offshore fishery closed area on the Scotian Shelf. Mar Ecol Prog Ser 2002, 240:249-265.

79. Hutchings JA: Influence of population decline, fishing and spawner variability on the recovery of marine fishes. J Fish Biol 2001, 59(suppl. A)):306-322.

80. Edgar GJ, Barrett NS: Short term monitoring of biotic change in Tasmanian marine reserves. J Exp Mar Biol Ecol 1997, 213(2):261-279.

81. Goni R, Renones O, et al: Dynamics of a protected Western Mediterranean population of the European spiny lobster Palinurus elephas (Fabricius, 1787) assessed by trap surveys. Mar Freshw Res 2001, 52(8):1577-1587.

82. Babcock RC, Phillips BJC, Lourey AM, Clapin G: Increased density, biomass and egg production in an unfished population ofWestern Rock Lobster (Panulirus cygnus) at Rottnest Island, Western Australia. Mar Freshw Res 2007, 58:286-292. 
83. Hoskin MG, Coleman RA, von Carlshausen E, Davis CM: Variable population responses by large decapod crustaceans to the establishment of a temperate marine no-take zone. Can J Fish Aquat Sci 2011, 68:185-200.

84. Blyth RE, Kaiser MJ, Edwards-Jones G, Hart PJB: Implications of a zoned fishery management system for marine benthic communities. $J$ Appl Ecol 2004, 41:951-961.

85. Bradshaw C, Collins P, Brand AR: To what extent does upright sessile epifauna affect benthic biodiversity and community composition? Mar Biol 2003, 143:783-791.

86. Lambert Gl, Jennings S, Kaiser MJ, Hinz H, Hiddink JG: Quantification and prediction of the impact of fishing on epifaunal communities. Mar Ecol Prog Ser 2011, 430:71-86.

87. Clemente S, Hernandez JC, Brito A: Evidence of the top-down role of predators in structuring sublittoral rocky-reef communities in a Marine Protected Area and nearby areas of the Canary Islands. ICES J Mar Sci 2009, 66:64-71.

88. Clemente S, Hernández JC, Brito A: Context-dependent effects of marine protected areas on predatory interactions. Mar Ecol Prog Ser 2011, 437:119-133.

89. Sala E, Zabala M: Fish predation and the structure of the sea urchin Paracentrotus lividus populations in the NW Mediterranean. Mar Ecol Prog Ser 1996, 140:71-81.

90. Sala E, Ribes M, Hereu B, Zabala M, Alvar V, Coma R, Garrabou J: Temporal variability in abundance of the sea urchins Paracentrotus lividus and Arbacia lixula in the northwestern Mediterranean: comparison between a marine reserve and an unprotected area. Mar Ecol Prog Ser 1998, 168:135-145.

91. Tupper M, Rudd MA: Species-specific impacts of a small marine reserve on reef fish production and fishing productivity in the Turks and Caicos Islands. Environ Conserv 2002, 29(4):484-492

92. Collie JS, Hall SJ, Kaiser MJ, Poiner IR: A quantitative analysis of fishing impacts on shelf-sea benthos. J Anim Ecol 2000, 69:785-798

93. Kaiser MJ, Clarke KR, Hinz H, Austen MCV, Somerfield PJ, Karakassis I: Global analysis of response and recovery of benthic biota to fishing. Mar Ecol Prog Ser 2006, 311:1-14.

94. Hinz H, Prieto V, Kaiser MJ: Trawl disturbance on benthic communities: chronic effects and experimental predictions. Ecol App/ 2009, 19:761-773.

95. Dimech M, Camilleri M, Hiddink JG, Kaiser MJ, Ragonese S, Schembri PJ: Differences in demersal community structure and biomass size spectra within and outside the Maltese Fishery Management Zone (FMZ). Sci Mar 2008, 72(4):669-682

96. Hastings A, Botsford LW: Comparing designs of marine reserves for fisheries and for biodiversity. Ecol App/ 2003, 13(1):S65-S70.

97. Roberts CM, Branch G, Bustamente RH, Castilla JC, Dugan J, Halpern BS, Lafferty KD, et al: Application of ecological criteria in selecting marine reserves and developing reserve networks. Ecol App/ 2003, 13(1):215-228.

98. Chiappone M, Sullivan-Sealey KM: Marine reserve design criteria and measures of success: Lessons learned from the Exuma Cays Land and Sea Park, Bahamas. Bull Mar Sci 2000, 66(3):691-705

99. Stewart GB, Kaiser MJ, Cote IM, Halpern BS, Lester SE, Bayliss HR, Pullin AS: Temperate marine reserves: global ecological effects and guidelines for future networks. Conserv Lett 2009, 2(6):243-253.

100. Anderson MJ, Millar RB: Spatial variation and effects of habitat on temperate reef fish assemblages in northeastern New Zealand. J Exp Mar Biol Ecol 2004, 305:191-221.

101. Monaco ME, Friedlander AM, Caldow C, Hile SD, Menza C, Boulon RH: Long-term monitoring of habitats and reef fish found inside and outside of the US Virgin Islands Coral Reef National Monument: a comparative assessment. Caribb J Sci 2009, 45:338-347.

102. Francour $P$ : The effect of protection level on a coastal fish community at Scandola. Corsica Rev Ecol (Terre Vie) 1991, 46:65-81.

103. Micheli F, Benedetti-Cecchi L, et al: Human impacts, Marine protected areas, and the structure of Mediterranean reef assemblages. Ecol Monogr 2005, 75(1):81-103

104. Valle C, Bayle-Sempere JT: Effects of a marine protected area on fish assemblage associated with Posidonia oceanica seagrass beds: temporal and depth variations. J Appl Ichthyol 2009, 25(5):537-544.

105. Jouvenel JY, Pollard DA: Some effects of marine reserve protection on the population structure of two spearfishing target-fish species, Dicentrarchus labrax (Moronidae) and Sparus aurata (Sparidae), in shallow inshore waters, along a rocky coast in the northwestern Mediterranean Sea. Aquat Conserv Mar Freshwat Ecosyst 2001, 11(1):1-9.
106. Watson M, Ormond RFG: Effect of an Artisanal Fishery on the Fish and Urchin Populations of a Kenyan Coral-Reef. Mar Ecol Prog Ser 1994, 109(2-3):115-129.

107. Acosta CA, Robertson DN: Comparative spatial ecology of fished spiny lobsters Panulirus argus and an unfished congener P. guttatus in an isolated marine reserve at Glover's Reef atoll, Belize. Coral Reefs 2003, 22(1):1-9.

108. Westera M, Lavery $P$, Hyndes $G$ : Differences in recreationally targeted fishes between protected and fished areas of a coral reef marine park. J Exp Mar Biol Ecol 2003, 294(2):145-168.

109. Monaco ME, Friedlander AM, Caldow C, Christensen JD, Rogers C, Beets J, Miller J, Boulon R: Characterising reef fish populations and habitats within and outside the US Virgin Islands Coral Reef National Monument: a lesson in marine protected area design. Fish Manag Ecol 2007, 14(1):33-40.

110. Francini RB, de Moura RL: Dynamics of fish assemblages on coral reefs subjected to different management regimes in the Abrolhos Bank, eastern Brazil. Aquat Conserv Mar Freshwat Ecosyst 2008, 18(7):1166-1179.

111. Chaves LDC, Monteiro-Neto C: Comparative analysis of rocky reef fish community structure in coastal islands of south-eastern Brazil. $J$ Mar Biol Assoc UK 2009, 89(3):609-619.

112. Edgar GJ, Barrett NS, Crane K, Bancroft K: Ecosystem monitoring of subtidal reefs in different management zones of the Jurien Bay Marine Park 1999-2007. Project Report. Hobart: Tasmanian Aquaculture and Fisheries Institute; 2009.

113. Coleman FC, Figueira WF, Ueland JS, Crowder LB: The impact of United States recreational fisheries on marine fish populations. Science 2004, 305:1958-1960.

114. Cooke SJ, Cowx IG: The role of recreational fishing in global fish crises. Bioscience 2004, 54:857-859.

115. McLean DL, Harvey ES, Fairclough DV, Newman SJ: Large decline in the abundance of a targeted tropical lethrinid in areas open and closed to fishing. Mar Ecol Prog Ser 2010, 418:189-199.

116. Hernandez JC, Clemente S, Sangil C, Brito A: Actual status of the sea urchin Diadema aff. antillarum populations and macroalgal cover in marine protected areas compared to a highly fished area (Canary Islands - eastern Atlantic Ocean). Aquat Conserv Mar Freshwat Ecosyst 2008, 18(7):1091-1108.

117. Forcada A, Valle C, et al: Effects of habitat on spillover from marine protected areas to artisanal fisheries. Mar Ecol Prog Ser 2009, 379:197-211.

118. Cinner JE, Marnane MJ, McClanahan TR: Conservation and community benefits from traditional coral reef management at Ahus Island, Papua New Guinea. Conserv Biol 2005, 19(6):1714-1723.

119. lacchei M, Robinson P, Miller KA: Direct impacts of commercial and recreational fishing on spiny lobster, Panulirus interruptus, populations at Santa Catalina Island, California, United States. N Z J Mar Freshw Res 2005, 39:1201-1214

120. Asch RG, Collie JS: Changes in a benthic megafaunal community due to disturbance from bottom fishing and the establishment of a fishery closure. Fish Bull 2008, 106(4):438-456.

121. Grizzle RE, Ward LG, et al: Effects of a large fishing closure on benthic communities in the western Gulf of Maine: recovery from the effects of gillnets and otter trawls. Fish Bull 2009, 107(3):308-317.

122. Underwood AJ: Beyond BACl: the detection of environmental impacts on populations in the real, but variable, world. J Exp Mar Biol Ecol 1992, 161:145-178.

123. Jones PJS: Fishing industry and related perspectives on the issues raised by no-take marine protected area proposals. Mar Pol 2008, 32:749-758.

124. Hiddink JG, Hutton T, Jennings S, Kaiser MJ: Predicting the effects of area closures and fishing effort restrictions on the production, biomass, and species richness of benthic invertebrate communities. ICES J Mar SC 2006, 63:822-830.

doi:10.1186/2047-2382-2-4

Cite this article as: Sciberras et al:: Evaluating the biological

effectiveness of fully and partially protected marine areas. Environmental Evidence 2013 2:4. 